\title{
LA MURCIANA: DOS VERSIONES PARA UN CANTE MINERO
}

\author{
Sixto Manuel Herrero Rodes \\ Conservatorio Superior de Música "Manuel Massotti Littel” de Murcia
}

\begin{abstract}
Resumen:
Este artículo presenta uno de los estilos de cante minero quizás menos conocido y desarrollado en la práctica flamenca, La Murciana, y concretamente, dos versiones que hoy en día son más conocidas y reinterpretadas en el Festival Internacional del Cante de las Minas de La Unión. Mi trabajo se ha centrado, principalmente, en la investigación de su estructura formal y cadencial. Con este trabajo he pretendido aportar en la forma más sintética, clara y ordenada posible, el conjunto de informaciones que para mí han significado una nueva manera de acceder a un repertorio extraordinariamente rico, por ello, toda labor historiográfica ha quedado supeditada a la misión de instruirme y enriquecer mis conocimientos sobre este estilo musical.
\end{abstract}

Palabras Clave:

Cantes Mineros, El Rojo el Alpargatero, la letra minera, modalidad y tonalidad, estructura formal, análisis melódico y cadencial, cuadro esquemático.

\begin{abstract}
:
This article presents one of the styles of Minero singing, perhaps a not very well-known modality in Flamenco practice: La Murciana. More specifically, this article deals with two versions, which are nowadays the best known and repeatedly performed in the International Festival of "Cante de las Minas" in La Unión. My research is focused primarily on its formal and cadential structure. It is my intention to bring -in the most synthetic, clear and organized way-, all information that has meant to me a new way of accessing to an extraordinarily rich repertoire; therefore, any historical work has been subordinated to the mission of informing myself and enriching my knowledge about this musical style.
\end{abstract}

\section{Key Words:}

Miners singing, El Rojo el Alpargatero, miner lyrics, modality and tonality, musical structure, analysis of melody and cadences, schematic table.

\section{Los Cantes Libres y de Levante: los Cantes mineros}

El recorrido historiográfico que el lector hallará en este apartado fundamenta su contenido en un intento de conocer y entender los cantes mineros de acuerdo a sus orígenes en la geografía, la naturaleza de sus temas, a la relación con la historia, por supuesto a la raíz social y a todas aquellas perspectivas de la temática cultural o musical que he podido encontrar atractivas y pertinentes desde el punto de vista académico. Obviamente, esta labor ha ido encaminada a prepararme en una serie de conocimientos circunstanciales e históricos localizados en una región de España como es Murcia, y concretamente en la cuenca minera de La Unión y Cartagena, estudio que también me ha permitido ambientarme y formarme en aquellos temas que más tarde me han servido en mi labor investigadora musical sobre el estilo de cante minero denomina- 
do: Murciana. El interés que me ha suscitado desarrollar este complejo mundo acerca del origen, creación y personajes que intervinieron en la génesis y desarrollo de los estilos de cante minero, en última instancia, ha sido el de establecer los vínculos históricos necesarios que me permitieran clarificar posteriores actuaciones relacionadas con el análisis formal y musical de los estilos de cante minero, además de servir como antesala a futuros proyectos creativos. Este trabajo ha cumplido la misión de instruirme como compositor, y de esta manera, he intentado responder a mis necesidades expresivas acercándome y formándome en los cantes mineros respetando su riqueza y herencia antropológica y filológica.

Con el nombre de cantes libres se puede definir a una serie de palos flamencos que se interpretan sin el rigor del metro de compás y duración exclusiva, es decir, disfrutan de ritmo libre. Se cantan en compañía de la guitarra que, previamente, realiza una introducción de libre ejecución donde expone el tono y carácter en el que se va a realizar el cante. Además, la guitarra puede intervenir de manera independiente actuando como nexo de unión entre los diferentes tercios o partes del cante, a modo de interludios, menos extensos que la introducción, con la finalidad de no dejar desnudo al cante.

Originariamente, los cantes libres proceden de fandangos que poco a poco se fueron aflamencado. Debido a su origen, estos estilos están dotados de una cualidad musical más melódica y dulzona que el resto de cantes flamencos, aunque dependiendo del intérprete, estos estilos pueden alcanzar un mayor grado de flamenquización. Surgen a finales del siglo XIX y principios del siglo Xx, en la etapa de los Cafés Cantantes, lugares donde los estilos flamencos, en su versión de cantes libres, encuentran la vía propicia para su creación, desarrollo y expansión. Coincide su génesis con el apogeo de la actividad minera en las cuencas de Almería; Cartagena y La Unión en Murcia; Linares, La Carolina y Andujar en Jaén.

Como cantes mineros se denomina a todos aquellos estilos flamencos que dentro de los cantes libres y de Levante se distinguen como propios de las comarcas mineras de Almería, Jaén, Cartagena y la Unión. Es así como hoy conocemos a una serie de estilos de cante llamados: Tarantas, Tarantos, Mineras, Cartageneras, Murcianas y Levanticas. La letra de la copla se distingue por tratar asuntos temáticos cercanos al trabajo de las minas y sus entornos geográficos, además de tratar temas propios del resto de coplas flamencas como por ejemplo: amor, religión, muerte, etc.

El origen de estos cantes mineros debe ser abordado desde una perspectiva laboral sobre los problemas del trabajo en las minas y sus repercusiones sociales; por la aportación que ofrece el folklore popular, y trabajos extramineros: carreteros, venteros, troveros, pregoneros, agüeros, etc.; y la contribución que los cantaores semiprofesionales y profesionales aportaron en la génesis, estructura y expansión de estos estilos mineros. Mediante la interpretación de estos palos flamencos, estos cantaores dirigieron sus actuaciones hacia una nueva clase social que emerge del trabajo de las minas y sus riquezas, realizadas en su gran mayoría en los cafés de cante y demás locales asociados a estos menesteres: tabernas, ventas, bares de licores y de alterne. El conjunto de este contingente circunstancial proporcionó el variopinto entorno profesional en el que se acunaría y gestaría el cante minero.

Hacia 1840 llegó la fiebre de la minería a la sierra de Cartagena, La labor minera comenzó en los escoriales y terreras, desechos de la época romana, donde se rebuscaba el mineral. Con la llegada de los primeros emigrantes andaluces se cavan pequeñas galerías llamadas ratoneras que buscan vetas de 
galena. Esta labor se prolonga con la explotación intensiva de carbonatos de plomo en 1846 y el descubrimiento de la mina Bilbao del Barranco de Mendoza donde se encontró un importante filón de galena en 1848. Desde entonces hasta la década de los sesenta del siglo xx no se interrumpiría el trabajo minero en La Unión, aunque con muchos altibajos. Este apogeo minero de la Sierra de Cartagena propició una atracción de población minera Almeriense hacia esta zona. A este movimiento migratorio andaluz se sumará otro procedente de los pueblos y comarcas vecinas de esta cuenca minera. Se trata de las ciudades y pueblos de: Cartagena, Murcia, Mazarrón, Águilas, Totana, Fuente Álamo, Torre Pacheco, San Javier, San Pedro del Pinatar, Lorca, etc. Este hecho, provoca cierto abandono de las labores de origen de estos inmigrantes (como la agricultura) con la intención de buscar en la minería una mayor fuente de ingresos. Con esta avalancha de gentes, el paisaje de la zona quedó profundamente transformado con montañas de detritos mineros, fundiciones y caminos que van surgiendo en pos del desarrollo minero.

Seis fueron los hechos que propiciaron los cantes mineros. El primero estuvo ocasionado por la llegada de grandes masas de trabajadores mineros desde las cuencas andaluzas hasta La Unión, sobre todo procedentes de Almería y Jaén, andaluces que aportaron la cultura del cante. Con su actitud musical, fagocitaron en forma de flamenco todo tipo de letras y cantos populares autóctonos.

El segundo hecho lo podemos hallar en el desequilibrio económico y social que se produce en los diferentes sectores sociales de población, puesto que la clase trabajadora, no luchó tan solo contra los peligros de la mina y la explotación obrera. Debido a esta situación laboral, el obrero siente la necesidad de relatar su vida a través de manifestaciones artísticas que reflejan sus penas e inquietudes. Aparece pues la crónica de los hechos en el cante minero. El tercer hecho lo encontramos en la forma de explotación minera en partidas (arrendar las minas a sus propietarios para ser explotadas por trabajadores autónomos) que profesa un sentimiento de individualidad en las labores de trabajo. El minero constantemente se enfrenta en soledad al trabajo de la mina, la oscuridad de ésta anula el pensamiento colectivo por el de la necesidad de hallar una fortuna personal que mejore sus condiciones de vida y proporcione, dentro de lo posible, una salida hacia otro tipo de vida alejada del trabajo en la mina. El siguiente relato de Génesis García nos ofrece una perspectiva del sentir individual del obrero minero respecto a la fortuna y el devenir de la vida en el trabajo: "Para los mineros, habituales campesinos soleados del sureste, la traumática experiencia vital es la del pozo. Por eso se lamentan de la oscuridad como ningún otro pueblo tradicionalmente minero. Toda la vida del minero del luminoso sureste está pendiente de esa oscuridad, de esa muerte potencial que, en gran parte, se apodera de su cante:

El minero en su negrura,
siempre trabajando abajo,
corta piedra blanda y dura,
y con su mayor trabajo
va abriendo su sepultura. ${ }^{1}$.

1 García Gómez, G.: Cante Flamenco, Cante Minero. Una interpretación sociocultural. Murcia, Editorial Anthropos, 1993 , p.207. 
Este sentimiento individual quedará asociado al cante.

El cuarto hecho fue la aportación que hacen al cante, en forma de trasvase de información, trabajadores de oficios complementarios al trabajo en las minas, contribuyendo al afianzamiento y expansión del cante minero. Se trata de tratantes, comerciantes, arrieros y tartaneros, oficios realizados por solitarios seres que llevan de un lugar a otro aquellas coplas y cantes que van compendiando por los caminos, ventas y demás lugares que recorren.

El quinto hecho viene dado por el hábito de reunirse después del trabajo, en los momentos de esparcimiento, en establecimientos donde se servían bebidas alcohólicas, prostíbulos y cafés de cante, convirtiéndose en lugares de creación y recreación del cante. Este hecho es considerado como el vehículo que convierte el cante en una manifestación artística íntima y particular, puesto que estos lugares no podían ser considerados como centros de expansión de cultura popular.

El sexto hecho lo podemos hallar en el auge que experimenta el argot lingüístico creado y asociado a los modos y costumbres de los trabajos mineros. Este hecho proporciona a la letra minera una particular forma de expresión típica y espontánea de la zona. Se crea un lenguaje que incorpora los utensilios y herramientas de trabajo que enriquecerán el léxico de las letras mineras. Además, se agregan al vocabulario jergal alusiones al paisaje minero y urbanístico, transformado constantemente según los periodos de esplendor económico. Aparecen en la zona una serie de nombres propios asociados a personajes y lugares que se hacen populares y con ello, motivo de mención en las letras mineras. Podemos ver ejemplos de nombres como el de La Gabriela y El Rojo el Alpargatero (entre otros nombres propios); barrios míticos como el de Herrerías; minas como el cabezo Rajao; el Partidario (referido a la persona que explota la mina en forma de partidas); oficios como el de barrenero, etc. El resultado final es el de un lenguaje y entonación característica de la cuenca minera de la sierra de Cartagena.

Este sustrato musical y temático pudo complementarse con los cantes o canciones de madrugá, canciones que acompañaban a los mineros en sus desplazamientos hacia el trabajo en la sierra minera en los cambios de turno. Estas cancioncillas aportaron la mayor parte del contenido de la letra minera: condiciones de trabajo; el miedo a la muerte; temas amorosos; reivindicaciones sociales; la pobreza y la riqueza; temas urbanísticos y paisajísticos; problemas sanitarios; etc. Esta contribución temática alimenta el modo expresivo metafórico que predomina y caracteriza la letra de la copla minera.

Con la aparición de los cafés cantantes, a finales del siglo XIX, comienza el periodo de profesionalización del flamenco y la mayoría de los estilos de cante que han llegado hasta nuestros días. Estos locales se convierten en centros de acogida del espectáculo flamenco (cante y baile) abierto al público. Por primera vez el cante se asocia a un fin comercial, y con ello, el baile flamenco y el lucimiento del cantaor adquiere un grado preponderante, la voz ocupa prácticamente toda la atención. Esta forma de concebir el cante se denomina «cante adelante»o «cante alante», ya que se trata de estilos flamencos destinados a ser escuchados. Cuando estos cantes acompañan la danza se les denomina «cante atrás», puesto que la voz ocupa un segundo plano y la danza se erige en el objetivo principal del espectáculo. De los cantes alante surgirían los cantes libres y dentro de ellos los cantes mineros. Fue así como los cafés cantantes se instituyeron en centros de evolución y enriquecimiento de los cantes mineros. 
Gracias al esplendor económico que proporcionó la industria minera en la década de los setenta y ochenta del siglo XIX en las ciudades de Cartagena y La Unión, se produjo una ascensión de la burguesía que incentivó una ampliación urbanística modernista en ambas ciudades donde hay que destacar la calle mayor de La Unión, centro neurálgico de la ciudad que acogerá la gran mayoría de los cafés cantantes de la ciudad.

Paralelamente a este esplendor, ventorrillos, tascas, aguaduchos y prostíbulos, se convierten en centros donde partidarios ${ }^{2}$, propietarios, mineros, comerciantes y señoritos de familias acomodadas se reúnen con el pretexto de hallar un espacio de ocio y diversión. En estos lugares la nueva burguesía disfrutaba de su nuevo estatus bebiendo, oyendo cante y alternando con prostitutas. De cafés de cante tal y como se concibió en Sevilla el de Silverio quizás no se pueda hablar debido a que estos locales se encontraban asociados al consumo de bebidas en primera instancia. En muchos casos, se podía cantar flamenco de forma espontánea y circunstancial. Cuando este arte se realizaba de manera continua y organizada se les podía denominar como cafés de cante. El aficionado minero que gustaba del cante, junto a tartaneros y arrieros, y todos aquellos relacionados con el tema minero practicaban este arte, a su manera, en estos establecimientos. Más tarde, cantaores profesionales traídos para actuar en los cafés de cante, recogían las fuentes de información local musical, recreando y engrandeciendo los cantes mineros. Fue así como los cantos de madrugá fueron poco a poco aflamencados y engrandecidos por cantaores profesionales, y también como el sustrato folklórico que aportaron las masas de inmigrantes, venidos de Andalucía o de las localidades vecinas, se fueron sumando al proceso evolutivo de formación y desarrollo de los cantes mineros.

\section{Breve Relato sobre las vicisitudes de los Cantes mineros deSde Su génesis Con: El Rojo el Al- pargatero, don Antonio Chacón, Antonio Grau Dauset y el Festival del cante de las minas de}

\section{LA UNión.}

Fueron los cantaores locales pertenecientes a La Unión y Cartagena, llegados o nacidos allí, quienes tuvieron un papel primordial en la creación de los estilos mineros, como por ejemplo Antonio Grau Mora «El Rojo el Alpargatero» a quién se considera creador de los cantes mineros, y más tarde, su hijo Antonio Grau Dauset quién los recuperará de su olvido impulsando una nueva etapa de revalorización de los cantes mineros. Otro cantaor como Don Antonio Chacón contribuyó a su engrandecimiento y difusión. Este cantaor registró en 1913 una minera titulada «Soy del reino de Almería», denominada con el calificativo de «Minera de Pedro el Morato».

Antonio Grau Mora nació en Callosa del Segura (Alicante) en 1847. En 1868 es desplazado a Málaga para realizar el servicio militar, ciudad donde conoció y asimiló el flamenco. Al volver a su pueblo natal en 1870, retoma el trabajo familiar de alpargatero comenzando a viajar, posteriormente,

2 Los partidarios son mineros que trabajaban arrendando en pequeños partidos la mina. 
como comerciante en la venta de alpargatas por las cuencas mineras de Cartagena y Almería. Es en este período cuando inicia su formación como cantaor, dedicándose definitivamente en 1880 a este menester. Posteriormente se marcha a Málaga con su mujer, María del Mar Dauset. Allí alterna y comparte cante con las primeras figuras de la época, llegando a ser un buen intérprete de malagueñas. En 1885 se traslada a la Unión, donde regenta una posada y se da a conocer como cantaor. A partir de aquí, todo lo que se sabe sobre cómo fueron concebidos los cantes mineros por parte del Rojo, se convierte en una mera especulación de datos puesto que Antonio Grau no dejó documentos escritos ni grabaciones que certificasen las bases musicales y formales de su cante minero.

¿Qué circunstancias o factores favorecieron la aparición de ese genio creador de «El Rojo el Alpargatero», necesario en la creación y estructuración de los cantes mineros? El primer factor lo podemos hallar en el conocimiento que tiene del oficio de cantaor, recordemos que practicó este arte como profesional. El segundo factor es suponer que hubo de enriquecer su patrimonio musical gracias a los encuentros y experiencias que tuvo con otros artistas en Málaga, de los cantes recopilados por las cuencas mineras de Almería y Cartagena, mientras ejercía el oficio de vendedor ambulante de alpargatas, escuchando a mineros, arrieros, comerciantes y todas las gentes que forman el sustrato social del cante minero. Un tercer factor lo hallamos en la posibilidad que tuvo de disponer de un espacio para la práctica del cante, regentó una posada que más tarde ampliaría con la intención de crear un café de cante, lugar que destinaría a potenciar la interpretación del flamenco donde alternó con otros grandes cantaores. El cuarto factor lo descubrimos en la propia personalidad del Rojo, dotada de la independencia y autosuficiencia creadora necesaria en la elaboración del cante minero. El quinto y último de los factores lo podemos localizar en el propio ambiente minero de La Unión, entorno que proporciona a Antonio Grau la materia prima en la letra y temática del cante minero, recopilada al observar y escuchar los cantos de madrugá, canciones que los mineros entonan en su marcha al trabajo de las minas, con su trapico y su carburico, en los cambios de turno en el trabajo. Este sustento emocional se convierte en el punto de partida temático y musical en el que el Rojo se apoya para crear los nuevos tonos y giros melismáticos de medios tonos que identifican la estética de los cantes mineros.

Junto al Rojo aparece otro cantaor que invitado por el Alpargatero actúa en La Unión. Dotado de un gran talante para el cante, engrandece y revaloriza los cantes mineros. Se trata de Don Antonio Chacón, cantaor que escucha los cantes mineros en voz de Conchita la Peñaranda alrededor de 1886 y 1889 en Sevilla. Son sus viajes a La Unión, invitado por el Rojo alrededor de 1896, cuando definitivamente se relaciona con estos cantes mineros que escucha, sobre todo, de su anfitrión, asimilando e interiorizando sus formas y contenidos. Al mismo tiempo conoce y se familiariza con la región de Murcia, especialmente de la cuenca minera de la sierra de Cartagena, y la idiosincrasia de sus gentes. Poseyendo una gran dote para el cante gracias a las cualidades de su voz, la capacidad de interpretar y de clarificar las estructuras tonales y melódicas del flamenco, Chacón engrandece los cantes mineros y aporta un legado de grabaciones que realiza durante los años 1910, 1913, 1925 y 1929. Registra por primera vez la Cartagenera, las Tarantas Mineras, la Taranta Cartagenera y acuña el vocablo de minera para el cante que hoy conocemos como tal. 
A partir de la desaparición de El Rojo el Alpargatero en 1907 y de Antonio Chacón en 1929, y con el auge del fandango en la etapa de la Ópera flamenca, y con la decadencia de la minería que comenzó en la cuenca de Cartagena a partir de 1910, los cantes mineros caen, progresivamente, en el olvido y en desuso de los repertorios de concierto llegando a convertirse en completos desconocidos del público.

En la década de los años cincuenta del siglo xx, los cantes mineros iniciaron un proceso de recuperación, conservación y difusión que se ha prolongado hasta nuestros días. Dos son los acontecimientos que tienen lugar en este renacer. El primero de ellos fue la llegada a Cartagena, en 1952, de Antonio Grau Dauset, el hijo de El Rojo el Alpargatero cuya labor fue decisiva en la historia del cante minero. En primer lugar, porque en su estancia en Madrid, en su etapa de estudiante, volvió a recuperar los cantes que había oído en el café de su padre y a los artistas que por allí habían pasado. En segundo lugar, porque la amistad que le unía con Escacena favoreció que se convirtiera en cantaor profesional y, unido a sus grandes dotes para el arte en general, consiguió transmitir el cante minero desde su juventud. En tercer lugar, hacia 1952, Antonio Grau realiza una visita a Cartagena reencontrándose con la tierra que le vio crecer. En su afán por recuperar del olvido aquellos cantes que había aprendido en su infancia, buscó hasta que encontró la voz que pudiera recrear el arte que él llevaba dentro de sí mismo. Y así fue que halló a Antonio Piñana, en quién volcó toda su sabiduría enseñando los cantes mineros con el objetivo de recuperarlos definitivamente.

El segundo acontecimiento fue la organización del primer Festival de Cante de las Minas que se celebró en 1961 en La Unión. Este festival ayudó a recuperar los aspectos formales y musicales de los palos mineros característicos de esta ciudad. Con su organización revitalizó y conservó, en su pureza, los estilos y formas del cante minero y contribuyó a registrarlos en grabaciones. El festival significó un gran impulso mediático que garantizó su expansión y difusión: festivales, recitales, actos culturales, trabajos de investigación en las Universidades, recuperación de grabaciones antológicas y en formatos antiguos, conferencias, etc.

También otros cantaores, sobre todo locales, ayudaron a conservar y reelaborar los cantes mineros. Junto a los ya citados, podemos añadir los nombres de Perico Sopas, natural de Sevilla, considerado el primer maestro del Rojo. Se le atribuye la creación de la Levantica y la reestructuración de los cantes de Levante. Dos contemporáneos a Perico Sopas y el Rojo fueron: El niño de San Roque, minero y cantaor el cual transmitía en su cante el sufrimiento y la presión social. Juan el Albañil, considerado uno de los mejores taranteros de su tiempo. A Pedro el Morato, natural de Vera (Almería), se le considera un buen cantaor pero sobre todo un gran trovador. Un rival de Pedro el Morato en el trovo fue el mítico Pajarito.

La primera persona que exportó los cantes mineros fuera de la sierra de Cartagena hacia Andalucía fue Concha la Peñaranda, conocida como «La Cartagenera». Nacida en la Unión, conocía los cantes del Rojo que cantó con mucho éxito cuando se dedicó profesionalmente al cante. Otra cantaora Unionense fue Emilia Benito «La Satisfecha», quien tuvo mucha fama dentro y fuera de la Unión, y que fue la primera cantaora local que grabó una placa³

3 Se trata de una grabación de 1916 en placa de pizarra catalogada como Malagueña Levantina, titulada "Di a la guitarra que suene". 
Un minero que junto a Antonio Grau hijo contribuyó a la recuperación y conservación de los estilos mineros fue Eleuterio Andreu. Aunque siempre se negó a dedicarse profesionalmente al cante, fue ganador de la lámpara minera en 1964, galardón que el festival del cante de las minas otorga al mejor cantaor por mineras. En 1968 consigue el primer premio en cartageneras, en el mismo festival. Junto a Eleuterio aparece una figura del cante que lo ha sido todo para los cantes mineros, Antonio Piñana Segado, nacido en Cartagena, ganador de la primera lámpara minera del Festival de La Unión en 1961.

El Festival Nacional del Cante de las Minas, también ha servido de lanzamiento artístico a muchos cantaores que pasaron por su concurso. Así tenemos nombres como el de Manolo Romero; Luís de Córdoba; Encarnación Fernández, descendiente de una dinastía de guitarristas y cantaores unionenses. Otros cantaores que procedían de Cartagena y La Unión fueron: Miguel Caparrós; Pencho Cros; Antonio Ayala «el Rampa»; El Macareno; Maite Martín; Morenito de Levante; Antonio López Ferrer «El Camionero»; Antonio Castillo Sarabia«El Gaditano»; Manuel Ávila, entre otros. Mención especial he de hacer a Curro Piñana, ganador de la Lámpara Minera en el XxxviII Festival del Cante Minero de La Unión, nieto de Antonio Piñana.

\section{LA LETRA MINERA}

El estudio que a continuación voy a realizar de la letra minera tiene como objetivo llegar a adquirir los conocimientos necesarios con los que poder entender el contenido y temática del mensaje minero. Es por ello que he creído necesario dedicar un apartado a este menester con la misión de conocer de primera mano aquellos aspectos que, desde una perspectiva puramente informativa, puedan ayudar a enfrentarme mejor en mi investigación cuando me disponga a emprender el análisis formal y musical de los cantes mineros en general y en particular de La Murciana.

La letra minera, surge como una especie de manifiesto documental que cuenta los hechos cotidianos acaecidos en forma de crónicas que contempla temas sociales y relacionados con el trabajo en las minas y sus actividades complementarias. Se crea una jerga autóctona con expresiones vinculadas a las labores de faena en la mina y fuera de ella, así como de los oficios subsidiarios y costumbres en el trabajo.

El lenguaje utilizado en la letra minera deriva, en gran parte, de los movimientos migratorios que aportan letras procedentes del folklore de origen. Entre estos grupos de población podemos encontrar, andaluces procedentes de las zonas mineras de Almería y Jaén y trabajadores que proceden de los alrededores, sobre todo agricultores, que abandonan las labores del campo y se incorporan a la minería. Al mismo tiempo, florece un incipiente auge urbanístico, que en el caso de Cartagena se amplía al puerto, inspirando un nuevo lenguaje relacionado con los ambientes portuarios y metropolitanos. La variedad de gentes y lugares produce una progresiva vulgarización y entonación característica del habla de la zona. Podemos encontrarnos con expresiones lingüísticas de alto contenido en seseo, pérdida de consonantes finales en las palabras, sustitución de unas consonantes por otras (por ejemplo: agüelo por abue- 
lo; pare por padre; farta por falta, etc.) y uso de sinalefas que serán muy utilizadas en el cante minero. Es típico utilizar, en la letra minera, la forma verbal en primera persona como recurso expresivo.

La métrica de la copla minera está compuesta por cinco versos octosílabos de dos rimas alternas en consonante o en asonante. Se repite el primer o segundo verso, dependiendo por donde comience el cante, convirtiéndose en una estrofa de seis versos, también con rima alterna la gran mayoría. A veces en la Taranta se repite el último verso provocando una estrofa de siete versos y en ocasiones el primer verso se interpreta incompleto, como es el caso de las Cartageneras.

La temática minera fundamenta sus principios semánticos en aportar un mensaje pleno de contenido en cada estrofa a pesar de la economía de versos y sílabas. En cada estrofa es habitual encontrar el lenguaje característico de la zona.

El tema del trabajo en la mina abarca una gran cantidad de letras mineras. En su contenido podemos hallar temas referentes a la labor en el interior de la mina, como se puede apreciar en la siguiente letra:

En el fondo de una mina

Clamaba un minero así:

¡Ay! En que soledad me encuentro,

en mi compaña un candil

y mi compañero muerto ${ }^{4}$

Las secuelas que provoca el trabajo y sus enfermedades:

Me dejó medio cegato

el polvo de la terrera;

ahora gano el pan que como

cantando Cartageneras 5 .

La siniestralidad laboral:

Dime que llevas en el carro que tan despacico caminas. Llevo al pobre de mi hermano que un barreno en las minas le ha cortado las dos manos ${ }^{6}$.

4 Gerardo, J.; y Belade, F.: Sociedad y Cante Flamenco, el cante de las minas. Murcia, Editora Regional de Murcia, 1985, pp.108-109.

5 SÁez García, A.: La Copla Enterrada. La Unión, Ayuntamiento de La Unión, 1998, p.123.

6 Gerardo, J.; y Belade, F.: Sociedad y Cante Flamenco, el cante de las minas. Murcia, Editora Regional de Murcia, 1985 , p.109. 
Un ejemplo del tema de la muerte se puede apreciar en la siguiente letra:

Solo al minero le ayudan

el trabajo y el valor,

Corta piedra blanda y dura;

siempre de la muerte en pos,

va abriendo su sepultura.

Como guitarra sin cuerdas

se está quedando La Unión:

unos que mata la sierra

y otros que se lleva Dios?.

Las reivindicaciones sindicales sobre mejora de las condiciones de trabajo y remuneraciones también aparecen de la siguiente manera:

Monte arriba, sierra abajo,

con mi carburico en la mano,

camino del trabajico,

cuando pienso en lo que gano,

me vuelvo del tajico ${ }^{8}$.

Las relaciones patronales:

De la entraña de la mina

sale el rico mineral

para que tenga berlina

los hijos de don Pascual'.

Las reflexiones metafísicas existencialistas también quedan reflejadas de la siguiente manera:

Tos van como un estampío

a la boca de la mina,

y un niño quiere bajar,

que su padre no ha salío

abajo tiene que estar ${ }^{10}$.

7 Sáez García, A.: La Copla Enterrada. La Unión, Ayuntamiento de La Unión, 1998, p.115.

8 Gerardo, J.; y Belade, F.: Sociedad y Cante Flamenco, el cante de las minas. Murcia, Editora Regional de Murcia, 1985, p.110.

9 Sáez García, A.: La Copla Enterrada. La Unión, Ayuntamiento de La Unión, 1998, p.127.

10 García Gómez, G.: Cante Flamenco, Cante Minero. Una interpretación sociocultural. Murcia, Editorial Anthropos, 1993, p.276. 
También se contempla otros temas genéricos de los mineros como por ejemplo:

$$
\begin{aligned}
& \text { Ve y dile al malacatero } \\
& \text { que no se asuste por ná; } \\
& \text { que amaine el esportón ligero, } \\
& \text { que con la pierna quebrá } \\
& \text { sube Pepe el pedricero }{ }^{11} \text {. }
\end{aligned}
$$

El poder del propietario sobre el obrero se refleja en la letra que habla del cobro en forma de vales como una injusticia social

Mal dolor les dé a los vales

y al borde que los crió,

que, por no pagar con reales,

aun estoy soltero yo $^{12}$.

El tema del amor se muestra mediante un vocabulario más desenfadado y liviano. Nos habla del amor que se tiene sobre la persona deseada, a la esposa, a la madre y al hermano:

Date prisa, tartanero, por llegar pronto a la Unión, que en el Hospital Minero

se está muriendo mi hermano

de la explosión de un barreno ${ }^{13}$.

También aparece en muchas coplas la invocación a la raíz genealógica del personaje en cuestión:

Mi abuelo fue bolichero

mi tío almadrabero,

mi padre es jabeguero

y los hijos de mi padre

todos somos marineros ${ }^{14}$.

11 ID.: Íbid., p.277.

12 ID.: Íbid., p.294

13 ID.: Íbid., p.281.

14 SÁez García, A.: La Copla Enterrada. La Unión, Ayuntamiento de La Unión, 1998, p.137. 
El tema religioso aparece con frecuencia como un vínculo con el más allá y como un refugio del espíritu ante la inseguridad en el trabajo y las afecciones de la vida:

$$
\begin{aligned}
& \text { Soy minero temerario } \\
& \text { y con orgullo sincero } \\
& \text { llevo al pecho un relicario } \\
& \text { con la Virgen del Rosario } \\
& \text { y el Cristo de los Mineros }{ }^{15} \text {. }
\end{aligned}
$$

La anécdota en la copla actúa como noticiero de lo cotidiano, informa y advierte:

Dicen que la tal Gabriela, la de la copla minera, siempre fue mujer cualquiera.

En el cante era canela

y por Levante puntera (...)

Al que se mee en esta esquina

se le rebaja el jornal,

o se le hecha de la mina.

Y, pa que no lo haga más, se le corta la minina ${ }^{16}$.

Se habla del cante, de la minera, de la taranta, de la Cartagenera y, en menor medida, del taranto, totanera y sanantonera dentro de la misma copla:

$$
\begin{aligned}
& \text { Cante por sanantoneras } \\
& \text { del barrio de San Antón; } \\
& \text { la copla cartagenera } \\
& \text { más bella de este rincón } \\
& \text { y de su cuenca minera }{ }^{17} \text {. }
\end{aligned}
$$

15 ID.: Íbid., p.147.

16 García Gómez, G.: Cante Flamenco, Cante Minero. Una interpretación sociocultural. Murcia, Anthropos, 1993, pp.269-270

17 Salom Amengual, A.: Los Cantes Libre de Levante. Murcia, Editora Regional de Murcia, 1982, p.136. 
También se escribe sobre los lugares que trata la copla como por ejemplo citar en una Cartagenera a la ciudad de Cartagena o con el apelativo con el que se denomina a los oriundos de esta ciudad "Cartageneros":
Lloraba una cartagenera
a los pies de un soberano.
Por Dios y por la santa Magdalena,
no se lleven a mi hermano
al Peñón de la Gomera ${ }^{18}$.

También se cita a los cantaores que practican el cante: El Rojo, Antonio Grau hijo, Eleuterio Andreu, Antonio Piñana, Pencho Cros, Encarnación Fernandez, Manolo Romero, Pedro el Morato, entre otros. Es popular:
"Fueron los firmes puntales
del cante puro minero
«La Peñaranda», «Chilares», «el Rojo el Alpargatero»
$\mathrm{y} \ll$ Enrique el de los Vidales»"19.

También la podemos encontrar de la siguiente manera:
"Fueron los firmes puntales
del cante cartagenero
la Peñaranda, Chilares,
el Rojo el Alpargatero
y Enrique el de los Vidales"20.

La Toponimia del lugar queda nombrada en ciudades y barrios que formaban parte de la cuenca minera como por ejemplo:

\section{De Cartagena a Herrerías \\ han levantao una pared,}

18 ID.: Íbid., p.140.

19 Sáez García, A.: La Copla Enterrada. Ayuntamiento de La Unión, La Unión 1998, p.64. p.246.

20 García Gómez, G.: Cante Flamenco, Cante Minero. Una interpretación sociocultural. Murcia, Anthropos, 1993, 
por la pared va la vía

y por la vía va el tren

¡y dentro la prenda mía! ${ }^{21}$.

Junto a estos lugares, aparecen nombres de calles:

En la calle Canales

se me perdió mi sombrero.

¡Quién se lo vino a encontrar:

el Rojo el Alpargatero

y no me lo quiso dar!22

De minas famosas o fabricas de fundición; paisajes típicos de la zona:

$$
\begin{aligned}
& \text { Tengo una mina en Portmás } \\
& \text { y un lavao en El Corguel } \\
& \text { y una jaca por colao } \\
& \text { que camina más que el tren: } \\
& \text { ¡yo ya soy un potentao! }{ }^{23}
\end{aligned}
$$

Nombres de cafés o tabernas populares:

Se quemó el Café Habanero

no lo pueden levantar,

¡Levantadlo, caballeros,

sólo por oír cantar

al Rojo el Alpargatero! ${ }^{24}$

$\mathrm{Y}$ alusiones al puerto y al mar:

Cartagena de Levante

puerto de mar venturoso,

refugio de navegantes

y de los barcos reposo ${ }^{25}$.

21 SÁEz García, A.: La Copla Enterrada. La Unión, Ayuntamiento de La Unión, 1998, p.155.

22 ID.: Íbid., p.153.

23 García Gómez, G.: Cante Flamenco, Cante Minero. Una interpretación sociocultural. Murcia, Editorial Anthropos, 1993, p. 221.

24 ID.: Íbid., p.246.

25 Sáez García, A.: La Copla Enterrada. La Unión, Ayuntamiento de La Unión, 1998, p.137. 
Dos mujeres se hicieron muy populares provocando su aparición en la letra minera, La Gabriela que regentaba una especie de bar de copas, de cante y de alterne:

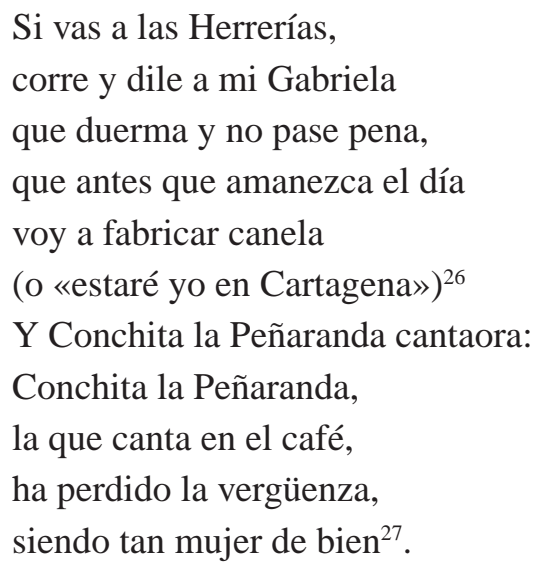

Hallamos otro personaje, minero él, cuyo nombre lo encontramos en la siguiente copla que habla de su situación personal:
“¡Válgame Dios, tío Rufino
las vueltas que el mundo da!
Siendo un minero tan fino, haber venido a parar
a echarle granza al molino" 28 .

\section{LA MODALIDAD Y TONALIDAD EN EL CANTE MINERO}

La materia prima que nutre gran parte de este trabajo es la música viva, que es la forma en la que un fenómeno como los cantes mineros han nacido y se han convertido en tradición sin necesidad de esa herramienta tan presente y necesaria para explicar nuestra tradición occidental culta como es el lenguaje musical escrito. Todas las versiones de Murciana que me dispongo a estudiar, han sido sometidas a una dinámica de trabajo aplicada al análisis en todas aquellas facetas que he creído relevantes según mi óptica de creador: la formal, la modal, la cadencial y la estética. Probablemente tam-

26 García Gómez, G.: Cante Flamenco, Cante Minero. Una interpretación sociocultural. Murcia, Editorial Anthropos, 1993, p. 270

27 ID.: Íbid., p.266.

28 ID.: Íbid., p.226. 
bién porque observo el fenómeno como un creador que ha forjado sus herramientas en una tradición musical escrita, la primera cuestión que debía emprender para ese trabajo minucioso era convertir esa música a los signos de la notación musical que acostumbro a utilizar en mi propio trabajo, es decir proporcionar una transcripción rigurosa de cada uno de los ejemplos que concedieran valor a mis reflexiones analíticas. El cante minero, melódicamente, se caracteriza por utilizar en su interpretación una gran mayoría de intervalos formados por grados conjuntos, sin grandes saltos interválicos que cuando se utilizan se colocan al principio de cada tercio o aislado en el transcurso del cante. El sistema musical sobre el que se sustenta los procesos melódicos es la modalidad. El modo utilizado en el cante minero es el modo griego «Frigio de $\mathrm{mi}^{29}{ }^{2}$, también conocido como el modo gregoriano «Deuterius Auténtico». El modo puede aparecer en mi o en cualquiera de sus transposiciones. Los semitonos se encuentran entre los grados VI-V y II-I en sentido descendente. En el siguiente ejemplo podemos ver el modo Frigio de mi con los números romanos indicando los grados de la escala descendente que forma el modo. También podemos ver la distancia interválica de sus grados que no varía al ser transportada a otro tono modal:

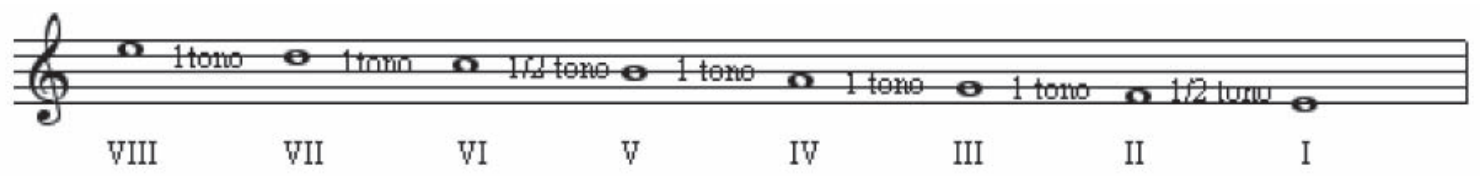

Ejemplo 1. Modo frigio de Mi.

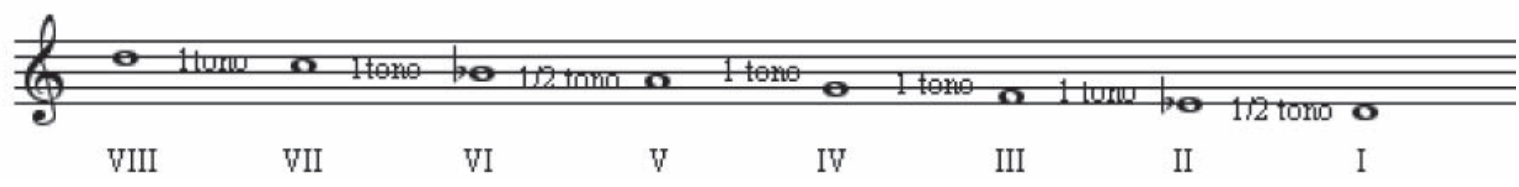

Ejemplo 2. Modo frigio de Re, Transposición a segunda mayor descendente.

La armadura del modo corresponde a la tonalidad formada por el grado tonal resultante de la tercera mayor inferior del primer grado modal. En el caso de mi frigio correspondería a Do Mayor, sexto grado modal, y la tonalidad del modo menor a La menor, cuarto grado modal.

29 De aquí en adelante adoptaré el nombre de «Frigio de Mi» como la escala modal del cante minero porque los teóricos de la armonía musical clasifican y denominan como cadencia flamenca y andaluza aquellas que se producen en base al comportamiento cadencial de este modo. 


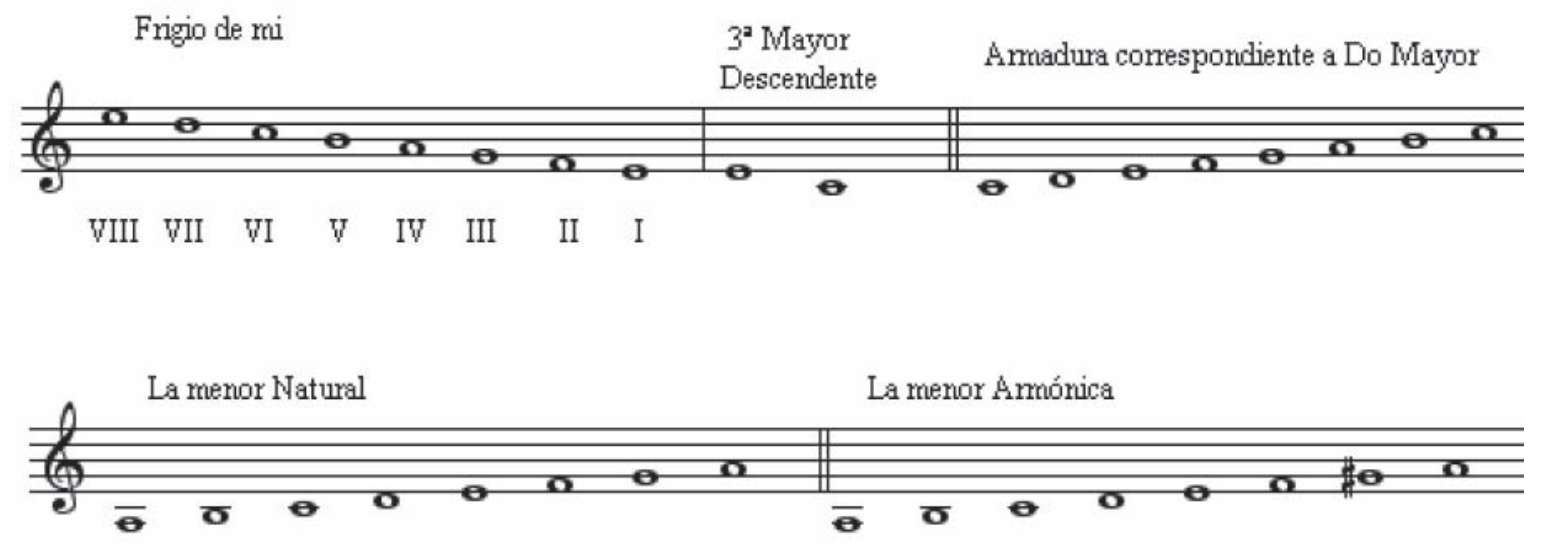

Ejemplo 3. Relación entre el modo frigio y las tonalidades mayores y menores.

Otra característica que presentan los cantes mineros es el uso del quinto grado modal rebajado medio tono indicado con el símbolo bv.

PENTACORDO SUPERIOR

\begin{tabular}{|c|c|c|c|c|c|c|c|}
\hline$a$ & & $\infty$ & be & $\infty$ & $1 \tan 0$ & 8 & \\
\hline VIII & VII & VI & $\mathrm{bV}$ & IV & III & II & I \\
\hline
\end{tabular}

Ejemplo 4. Modo frigio de Mi con bv.

También descubriremos en el comportamiento de la voz en los cantes mineros el uso alterno del v y bv como recurso melódico y melismático, además, el bv se puede utilizar como proceso cadencial. En muchas ocasiones, ambos grados, son utilizados indistintamente en un mismo giro melódico.

Los acordes resultantes de cada uno de los grados del modo confieren a éste una doble posibilidad. En primer lugar, aportan la sonoridad característica del modo. En segundo lugar, proporciona los posibles acordes que aportan funciones y sonoridades tonales. En el siguiente ejemplo, podemos ver como el acorde formado sobre II modal se puede considerar como perfecto mayor de Fa Mayor ${ }^{30}$. Tam-

30 Sobre todo cuando en el cante aparece el bv, sonoridad que corresponde a Fa Mayor si hablamos del modo de Mi. 
bién, el III modal lo podríamos clasificar como un acorde perfecto mayor sobre el quinto grado de la tonalidad mayor del modo, Do Mayor. La triada construida sobre el IV se podría utilizar como el acorde perfecto menor sobre el I de La menor, tonalidad menor del modo frigio de mi. El vi modal, correspondería al I perfecto mayor del modo mayor del modo, Do Mayor. El vir modal podría considerarse como acorde sobre I menor de Re menor, modo menor.

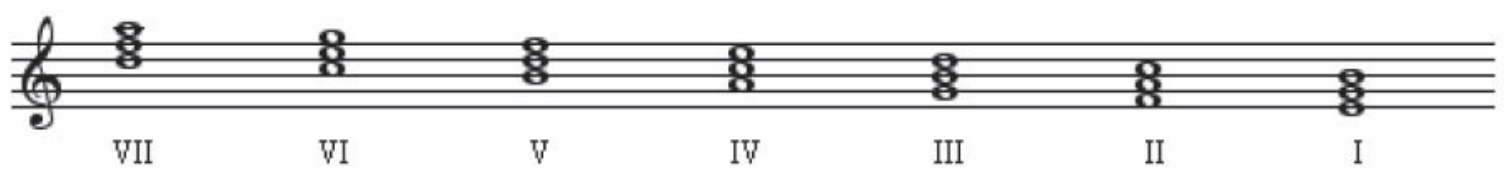

Ejemplo 5. Acordes modales del modo frigio de Mi.

Al mismo tiempo, estos acordes podrían estar asociados a una serie de funciones tonales de carácter secundario. Si el v aparece con si natural, perfectamente podría realizar cualquier función de dominante de Do Mayor o de dominante secundaria de La menor. Cuando aparece con bv, puede realizar la función de subdominante de Fa Mayor ó Re menor. En el caso del I modal, si en su triada aparece el si bemol, podría realizar la función de dominante de Fa Mayor y de dominante secundaria de Re menor. También podría considerarse como un acorde de dominante de La menor con la quinta rebajada ${ }^{31}$. Al final de cada tercio se resuelve con un proceso cadencial. Las secciones principales del cante finalizan en una cadencia sobre el I antecedida del II como dominante modal. Cuando en la cadencia final sobre el I aparece un acorde cuya triada presenta la tercera alterada medio tono ascendente obtenemos la «Cadencia Flamenca». Esta cadencia es conocida por su carácter melódico como por el armónico. La resolución armónica la apreciaremos con mayor claridad en la guitarra. Melódica y armónicamente la Cadencia Flamenca la distinguiremos de la siguiente manera:

31 Se podría considerar como el acorde de séptima de dominante con la quinta rebajada, que en la armonía tradicional se relaciona con el acorde de sexta Aumentada.

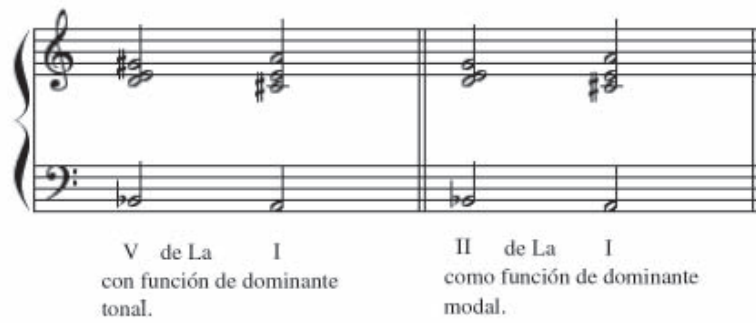




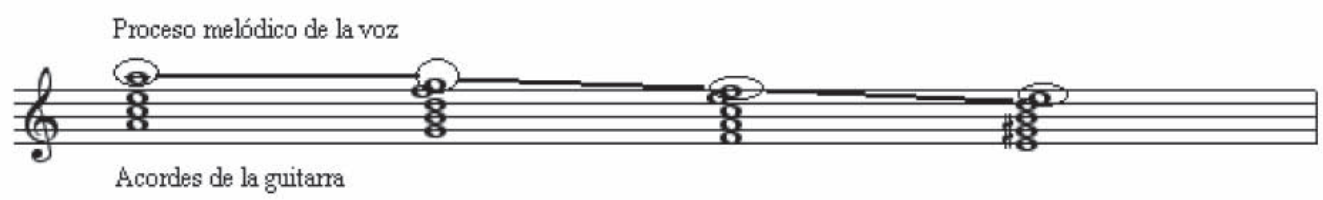

Ejemplo 6. Cadencia flamenca.

Cuando consideramos el acorde sobre la tónica modal como quinto grado de La menor, se forma la llamada «Cadencia Andaluza», veamos un ejemplo:

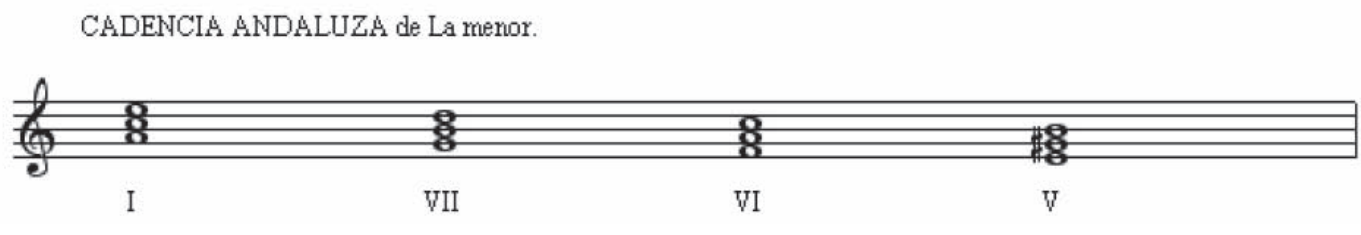

Ejemplo 7. Cadencia Andaluza.

\section{ESTRUCTURA FORMAL DE LOS CANTES MINEROS}

El esquema formal de los cantes mineros permite realizar una división en partes bien diferenciadas. Se pueden distinguir cuatro partes que voy a denominar como: Introducción, Salida, el Cante de la copla (el cante en sí) y el Remate Final.

Introducción:

Preludio que realiza la guitarra donde expone el tono y carácter expresivo del cante. De duración indeterminada, su desarrollo está en manos del intérprete, y su carácter depende de sus dotes técnicas e interpretativas en primera instancia. En segunda instancia, su expresión está asociada a una serie de factores como: la inspiración que el instrumentista recibe del cantaor; el tipo de cante que se va a realizar; el mensaje de la copla; y el ambiente de la sala. El toque de la guitarra se ejecuta libre de metro de compás y ritmo, denominado «Toque por Tarantas» que se distingue por interpretarse utilizando «el acorde de taranta». Este acorde se construye con la posición de Fa\# Mayor ${ }^{32}$ en la guitarra que deja libres las cuerdas prima y segunda. La disposición del acorde que se produce es:

32 He utilizado como ejemplo de acorde el de Fa\# Mayor puesto que corresponde a la posición de cejilla utilizada por el guitarrista, digitación que permite cambiar de tono sin cambiar la disposición de los dedos en el acompañamiento de los cantes mineros. Algunos guitarristas han liberado esta posición con el propósito de alcanzar, a lo largo del mástil de la guitarra, mejores recursos expresivos en la interpretación. 


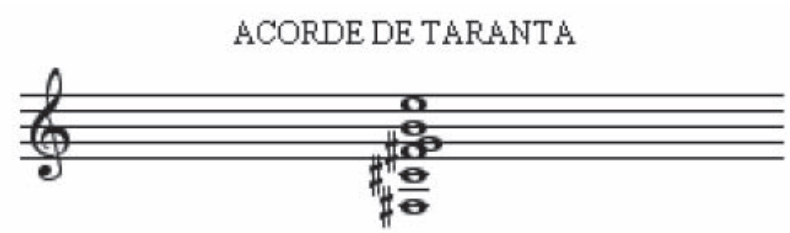

Ejemplo 8. Acorde de Taranta.

Otro recurso musical que utiliza la guitarra es la «Cadencia Flamenca». El resultado final es la construcción de un acorde sobre el grado tonal del modo con la tercera alterada medio tono ascendente, «tónica modal mayorizada». El siguiente ejemplo representa el acorde final sobre I con función de acorde perfecto mayor de Mi Mayor con la tercera alterada medio tono ascendente, Sol\#:

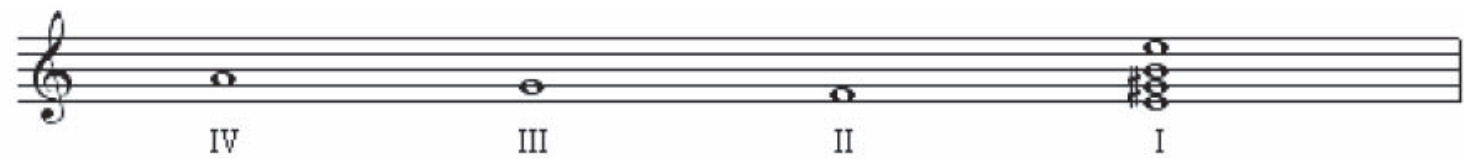

Ejemplo 9. Tónica modal mayorizada.

El uso de notas extrañas al modo es bastante frecuente, en forma de floreos y aproximaciones superiores e inferiores de medio tono sobre los grados i y IV. Este efecto produce en el toque una cierta sonoridad disonante, acción que aumenta el carácter dramático de estos cantes.

La Salida:

Se trata de un canto melismático realizado por el cantaor en compañía de la guitarra. Se interpretan mediante una serie de vocalizaciones onomatopéyicas características del flamenco entre las que podemos encontrar: ay, ia, ao, io, iao, ieo, iaui. En la modalidad de Cartagenera Grande y la versión de Levantica que hace Antonio Piñana se suprime este apartado.

En la mayoría de ocasiones, el cantaor comienza la Salida por el sexto grado modal y puede estar dividida en dos o más secciones. La cadencia final de la última sección se realiza sobre el I grado mayorizado (Cadencia Flamenca). Es habitual escuchar la sonoridad de bv en alguno de los fragmentos que componen la salida., salvo en raras ocasiones ${ }^{33}$. La voz se mueve por grados conjuntos, principalmente, formados por las notas del modo y en sentido descendente. Es raro encontrar saltos de tercera o cuarta una vez iniciada la Salida.

33 Por ejemplo en la Cartagenera que canta Cobitos con el título "Si vas a San Antolín" no utiliza bv. Otro ejemplo lo encontramos en la cantaora Encarnación Fernández en la interpretación de la Levantica titulada: "Se han levantao las minas". 
La guitarra, ofrece al cantaor el sustento modal en el que éste se mueve e intercala pequeños giros melódicos y sonidos aislados que concuerdan con cada una de las semicadencias del ayeo. Cuando la guitarra hace uso de un acorde, lo construye sobre triadas resultantes de cada uno de los grados del modo, es decir, surgen como acordes propios del modo. A continuación podemos ver un ejemplo de la salida de la minera que canta Pencho Cros "Se oye un grito en el Hundío", donde divide la Salida en dos secciones, realiza una semicadencia sobre el Sol, II del modo de Fa\#, la guitarra responde con la triada construida sobre el ir que podemos considerar como un acorde de tónica de Sol Mayor puesto que la voz, previamente ha utilizado Do natural, el final de la salida suena el acorde sobre i mayorizado:

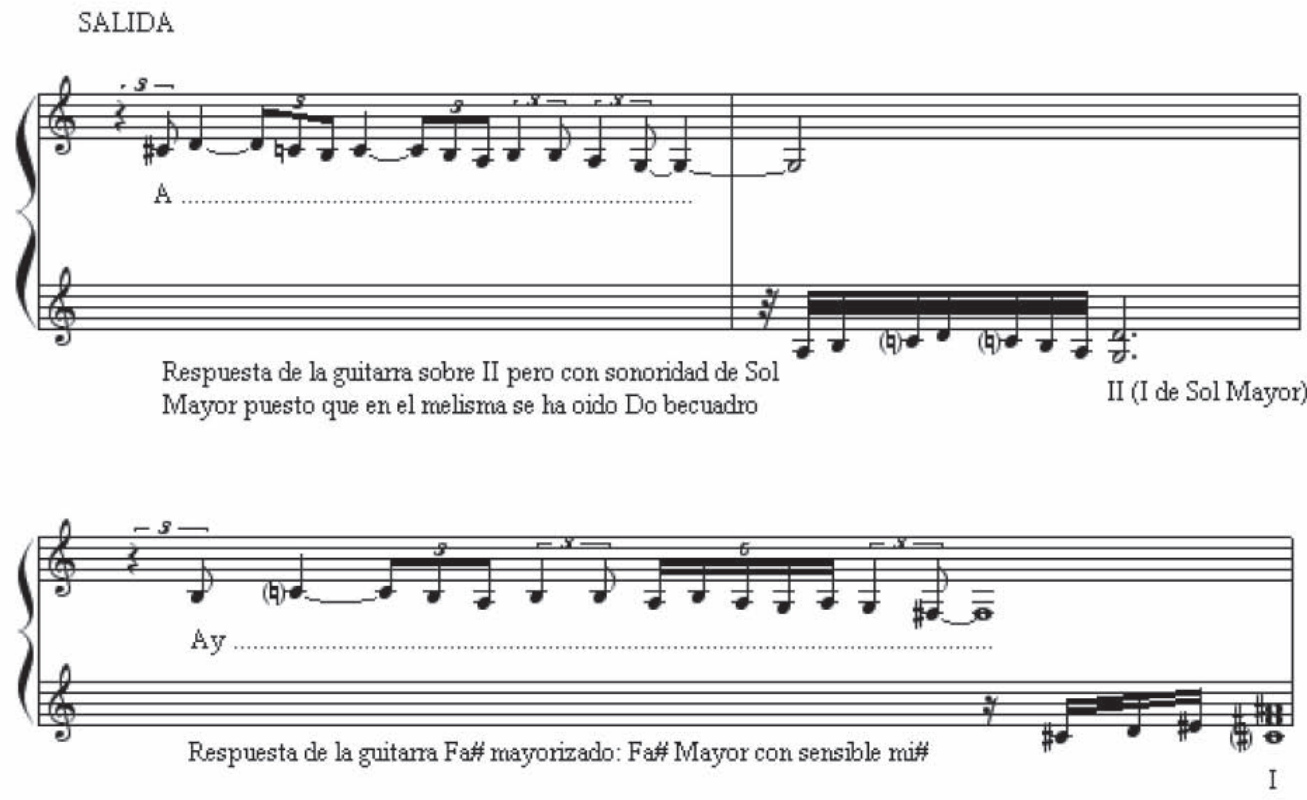

Ejemplo 10. Salida de"Se Oye un grito en el hundio", Pencho Cros. Transcripción realizada de: Festival Nacional del Cante de las Minas, Antología, vol. 1, RTVE, M-31744-2000.

Gracias a la Salida, el cantaor tiene la oportunidad de calentar la voz, entonar el modo en el que va a realizar el cante, introduce el carácter musical y estética de la pieza, y por último, manifiesta mediante el gesto, el estado emocional con el que se dispone a transmitirnos el mensaje flamenco y minero. También ayuda a mostrar las características técnicas y expresivas propias de cada cantaor; calidad y cualidad del timbre y textura de su voz; ámbito y tesituras que frecuenta; intensidad de la voz, sobre todo en tesituras altas; delicadas secuencias de giros melismáticos, suaves en las regiones graves; duración de los melismas; habilidad en el proceso de respirar y la consiguiente recuperación del tono tras ésta; capacidad de deslizarse y realizar giros melódicos a través de los grados del modo; presentación del vibrato de la voz y de su desgarre para crear el «rajo» flamenco, si lo hubiere. 
El Cante de la Copla:

Es el cante propio de la letra. Se divide en seis tercios y el remate final. Cada tercio corresponde a la interpretación de uno de los versos de la copla. El remate final, en ocasiones, se suprime, de tal manera que el final del cante coincide con el de la copla. Los tercios pueden quedar unidos por pequeños interludios que realiza la guitarra, en ocasiones también lo puede hacer el cantaor, acción que se denomina «ligar el tercio». En el caso de la Taranta, se puede repetir el último verso de forma parcial.

El cante de la copla puede estar sujeto a otra forma de organización interna en función del contenido de la letra (mensaje), expresión y estética del cante. Si consideramos estas tres premisas, al conjunto de los tres primeros tercios les denominaremos «Cante de Preparación». En esta sección, la letra del cante presenta el asunto o argumento de la letra; su intensidad en la interpretación no es demasiado elevada, sin grandes alardes interválicos y con una textura de timbre homogéneo en la voz. Al cuarto tercio lo denominaremos «Cante Valiente», de mayor brío y arresto interpretativo, la intensidad de la voz se eleva al máximo, sobre todo, en la cabecera del verso. De mayor dramatismo y tensión en la interpretación. El contenido de la letra propone cuestiones de signo reivindicativo, representa una protesta personal, expresa un deseo o denuncia sobre un hecho concreto. En algunos casos, el cantaor amplía el ámbito del cante valiente al quinto tercio, o bien lo cambia libremente de lugar ${ }^{34}$. Los últimos tercios del cante minero suelen presentar un carácter expresivo dulce, compuestos por delicados giros melódicos que en ocasiones recuerdan a un canto llano. Pueden estar formados por largos espacios musicales de naturaleza monofónica que polarizan hacia un solo sonido, a esta sección la denominaremos «Cante Liviano».

\section{El Remate Final:}

Se trata del final del cante, se interpreta a base de melismas en sentido descendente y compuestos por ayeos característicos del flamenco. La cadencia final se realiza desde el II, como dominante modal, y resuelve en I mayorizado que realiza la guitarra.

Por tanto, la estructura general de los cantes mineros presenta dos posibilidades, la primera construida en función de la naturaleza musical de sus partes:

1. Introducción de la Guitarra.

2. Salida del cantaor.

(Pequeño interludio de la guitarra)

34 El Cante de Preparación y el Cante Valiente para la Minera es invariable. En la Taranta, el primer tercio comienza con mucha fuerza y brío en la interpretación, disminuye la intensidad interpretativa poco a poco hasta el final del cante. Podríamos decir que en la mayoría de ocasiones, la Taranta presenta el Cante Valiente en el primer tercio. El resto de cantes mantiene aproximadamente esta estructura, su alteración tan sólo depende del contenido de la letra y de las características expresivas del cantaor. 
3. Cante de la Copla

- Primer tercio

- Segundo tercio

- Tercer tercio(Corresponde a la repetición del primer verso)

- Cuarto tercio

- Quinto tercio

- Sexto tercio

- (en la Cartagenera séptimo tercio)

4. Remate final (en ocasiones coincide con el último tercio)

Atendiendo al contenido de la letra y el carácter expresivo en la interpretación, podemos exponer el segundo esquema estructural del cante minero:

1. Introducción de la Guitarra.

2. Salida del cantaor.

(Pequeño interludio de la guitarra)

3. Cante de la Copla:

3.1 Cante de Preparación:

a. Primer tercio

b. Segundo tercio

c. Tercer tercio (Corresponde a la repetición del primer verso)

3.2 Cante Valiente:

d. Cuarto tercio

e. Quinto tercio

3.3 Cante Liviano:

f. Sexto tercio

g. (en la Cartagenera séptimo tercio)

3.4 Remate final (en ocasiones coincide con el último tercio)

\section{Análisis melódico y Cadencial de La Murciana}

Llegado a este apartado de mi estudio, he de advertir que el conjunto de informaciones que a continuación voy a exponer proceden de la información que de las transcripciones de La Murciana he podido extraer. Por tanto, obviaré todo contenido subjetivo que contengan juicios de valor personales acerca de cada una de las versiones objeto de mi investigación. Mi labor ha consistido en analizar la música desde el material musical que las transcripciones me han permitido extraer y respetando el cante tal y como hoy nos ha llegado. 
Cada tipo de cante tiene una manera específica de cadenciar, aunque en el final de la introducción, la salida y el cante de la copla se hace sobre el primer grado modal convertido en acorde mayorizado por la guitarra en todos los estilos de cante minero. En el análisis de los cantes mineros, es necesario estudiar la forma de acceder a las cadencias, por ello, en el estilo que voy a mostrar, la Murciana, indicaré una breve secuencia de grados melódicos y el intervalo utilizado para anticipar la cadencia final que le caracteriza, sobre todo, cuando mediante este comportamiento pueda ofrecer diferencias comparativas de un intérprete a otro.

Voy a enumerar una serie de premisas que han determinado los cauces por los que he encaminado mi trabajo de investigación. En primer lugar, debo advertir que el objetivo fundamental del estudio que he realizado sobre La Murciana lo he abordado desde la observación del proceder melódico de la voz, atendiendo al arranque interválico de cada una de las partes en las que ha quedado configurado este estilo y la manera de cadenciar en cada uno de sus finales. En segundo lugar, el análisis de los acordes respuesta de la guitarra en cada una de las cadencias tiene como finalidad traducir su función modal y tonal. En tercer lugar, la interválica más pequeña que utilicé en los ejemplos transcritos fue de medio tono. Es posible que aparezca en el cante original giros interválicos cuya distancia sea menor de medio tono, en estos casos no los consideré objeto de mi investigación referente al análisis del proceso cadencial, puesto que dicho comportamiento no significa un hecho consciente del interprete en ese sentido, sino más bien, una acción circunstancial de la voz en el cante que me ha servido en mis posteriores experiencias creativas. En cuarto lugar, los cantaores y cantes que he elegido para ser transcritos y analizados han sido seleccionados por el interés que sus interpretaciones prestan en mi investigación. En quinto lugar, el proceso de selección que he llevado a cabo para escoger las piezas transcritas ha sido determinado en base a la correcta construcción formal del cante y su rigor en la interpretación. Con la audición sonora he determinado: el modo, la melodía, los giros interválicos, el ritmo, el matiz y el timbre de las voces. En sexto lugar, la afinación temperada del piano a 440 vibraciones por segundo me ha servido como referencia para ubicar el tono o la tónica modal del cante ${ }^{35}$. Debo advertir que la afinación resultante puede diferir del tono original debido a las imperfecciones en el sistema de grabación y de reproducción, aunque todas las muestras que he utilizado han sido digitalizadas previamente. En séptimo lugar, el sistema de escritura musical que he utilizado en las transcripciones corresponde al tradicional occidental. Los grados del modo los designaré en números romanos como se puede ver en el siguiente ejemplo ${ }^{36}$ :

35 La tónica modal corresponde al primer sonido de la escala modal si la escribimos en el pentagrama en sentido ascendente. Esta tónica modal proporciona el nombre al modo y a sus posibles transposiciones, como por ejemplo: modo frigio de mi, modo frigio de la, etc. El sistema temperado de afinación consiste en dividir la escala de ocho sonidos en doce semitonos cuyas distancias interválicas son idénticas, en cuanto a la distancia y por consiguiente a su afinación.

36 Como se puede comprobar en este ejemplo, la escala modal aparece en sentido descendente. La razón de mostrar el modo de esta manera responde al uso melódico y cadencial en sentido descendente que tiene lugar en el cante. 


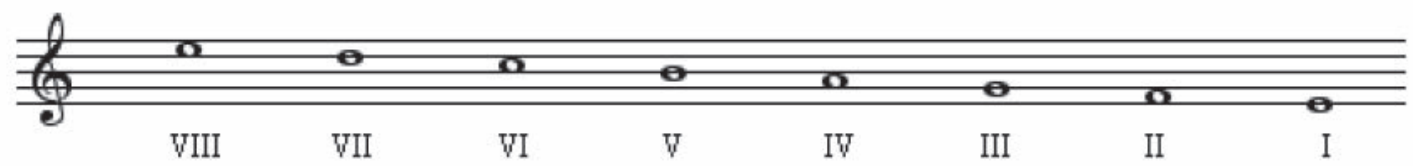

Ejemplo 11. Grados del modo frigio de Mi en sentido descendente.

En octavo lugar, cuando el quinto grado del modo aparezca alterado medio tono descendente lo indicaré como quinto grado rebajado cuyo símbolo aparecerá con la abreviatura: bv ${ }^{37}$.

La Murciana es el menos aflamencado de los cantes mineros, su procedencia es algo incierta, probablemente esta relacionada con la Taranta. Su copla está compuesta por cinco versos octosílabos en los que se repite el primero o segundo, y así la convierte en una copla de seis versos. En la interpretación de la Murciana, el quinto tercio está ligado al sexto por el cantaor, además se repite la letra del último verso, total o parcial. Ésta se encuentra a caballo entre las influencias musicales del folklore murciano, sobre todo de jotillas y parrandas murcianas, y las atribuciones flamencas que le proporciona el toque por tarantas de la guitarra y los giros de la voz.

Dos son los modelos de Murcianas que he analizado por el valor que desde el punto de vista estructural y musical presta a mi investigación. En primer lugar tenemos la cantada por «El Cojo de Málaga» titulada "Échese usted al vaciaero" ${ }^{38}$ de la que «El Rampa» ${ }^{39}$ hace una versión prácticamente igual y cuya letra es la siguiente:
Aperaor de la lavá,
échese usted al vaciaero,
y diga a Venancio Corral
¡ay! que con él batirme quiero,
Echese usted al vaciaero,
aperaor de la lavá.

En segundo lugar tenemos la Murciana que canta Manuel Ávila titulada "Araceli a ti te llaman"40 y cuya letra es:

37 A partir de ahora, vamos a poder comprobar como muchos ejemplos procedentes de las transcripciones de La Murciana y sus transposiciones, aparecerán notas indicadas con un becuadro cuando representen el quinto grado rebajado. En estos casos, el símbolo indicativo de este grado rebajado seguirá siendo el mismo, bv.

38 Transcripción realizada desde: "El Cojo de MálagA": Historia del Flamenco. Sevilla, Ediciones Tartesos, "Testimonios Flamencos, vol. 40", 1921.

39 Transcripción realizada desde: Ayala, Antonio, "El RAMPA”: Festival Nacional del Cante de las Minas. La Unión, RTVE, M-23690-2003, "Antología, vol. 4", 1988.

40 Transcripción realizada desde: Ávila, Manuel: Festival Nacional del Cante de las Minas. La Unión, RTVE, M-236902003, “Antología, vol. 4”, 1973. 


\section{Yo no quisiera quererte \\ ¡ay! Araceli, a ti te llaman prima \\ yo no quisiera quererte, porque en las minas de Araceli \\ tuvo mi padre la muerte, \\ Araceli, a ti te llamaban.}

La salida, en ambas, está dividida en dos secciones. Manuel Ávila comienza por Iv-bv y cadencia en la primera sección en II. La segunda sección comienza por I-II y cadencia en I. La cantada por «El Cojo de Málaga» es similar, excepto en la salida de la primera sección que la inicia: v-vi-bv. Veamos un ejemplo de la salida que realiza el «El Cojo de Málaga»:

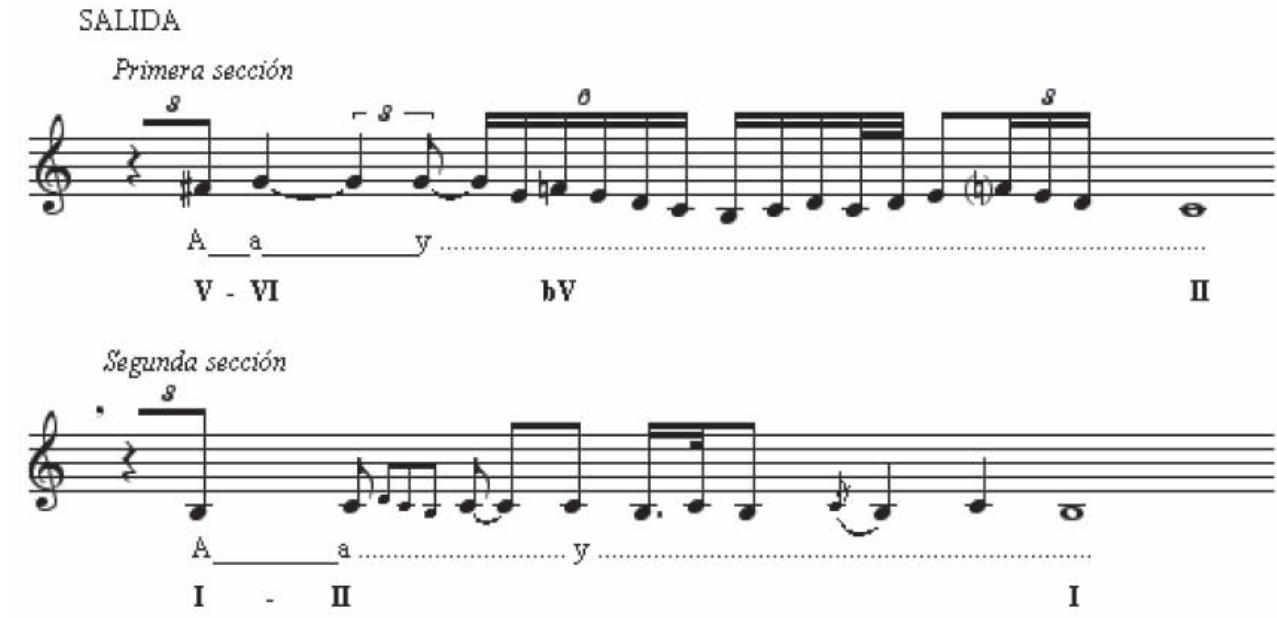

Ejemplo 12. Salida de la Murciana «El Cojo de Málaga»: “Échese usted al vaciaero”.

Este es el ejemplo de la salida que realiza Manuel Ávila:

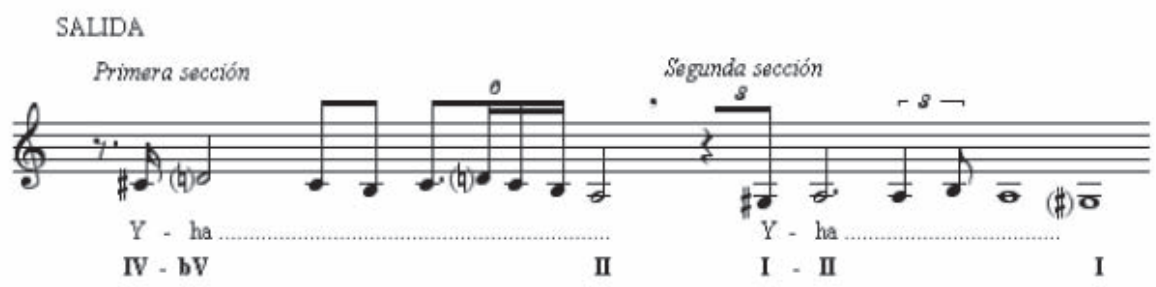

Ejemplo 13. Salida, Murciana, Manuel Ávila: “Araceli a ti te llaman”. 
Ambos cantaores interpretan las cadencias en las dos secciones de la salida en sentido descendente y por grados conjuntos. En la primera sección, utilizan la siguiente progresión: bv-IV-III-II. El acorde respuesta se realiza mediante la triada creada sobre II cuya función tonal podría ser de un acorde perfecto mayor de Fa Mayor (Mi frigio). La cadencia final de la salida corresponde a la cadencia flamenca con mi mayorizado.

Ambos inician el primer tercio melódicamente a partir del III. «El Cojo de Málaga» realiza la cadencia final del tercio en I, Manuel Ávila en v. «El Cojo de Málaga», en la conclusión de la cadencia realiza un giro característico, es una sucesión de grados conjuntos que alcanza una segunda mayor inferior a la tónica modal ${ }^{41}$. El orden de los grados es el siguiente: II-III-II-I-(-)VII ${ }^{42}$. Veamos este ejemplo:

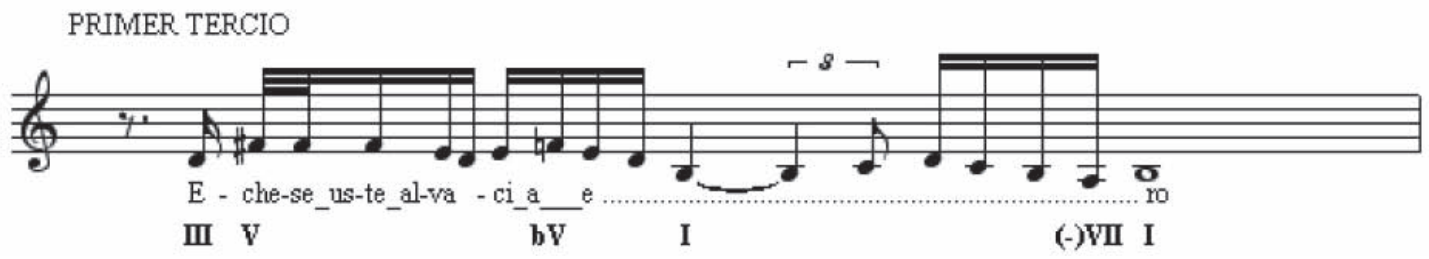

Ejemplo 14. $1^{\circ}$ Tercio. Murciana: “Échese usted al vaciaero”. «El Cojo de Málaga»

Manuel Ávila accede a la cadencia final del primer tercio en sentido descendente mediante un doble floreo superior e inferior sobre IV y resuelve en $\mathrm{v}$ :

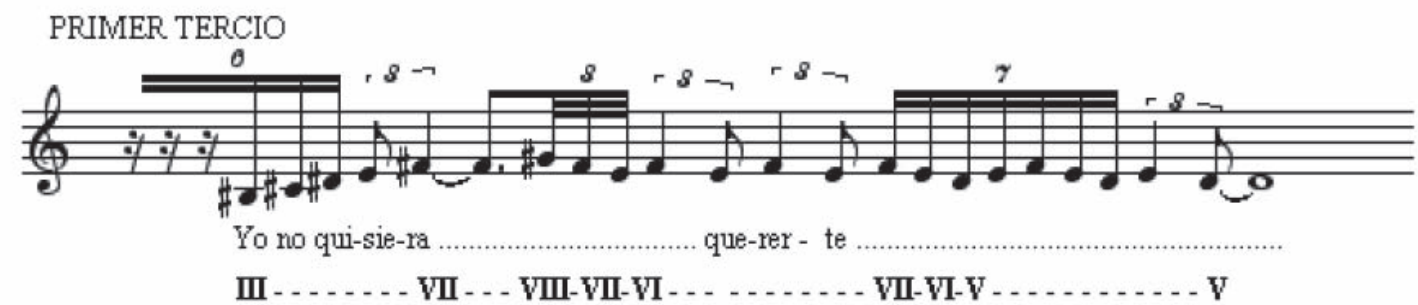

Ejemplo 15. $1^{\circ}$ Tercio. Murciana, Manuel Ávila: “Araceli a ti te llaman”.

41 En la música Gregoriana este tipo de cadencia se le denomina "Remisa" ya que la distancia del vil al I como resolución de cadencia es de un tono. También se le puede conocer como cadencia natural.

42 El símbolo (-)viI, corresponde al séptimo grado del modo situado una segunda Mayor inferior de la tónica modal. 
En la Murciana de «El Cojo de Málaga», el acorde respuesta se realiza sobre I. La función tonal podría ser de un acorde de III de la tonalidad mayor de Do Mayor de Mi frigio, (Sol Mayor en el tono original). El acorde respuesta en Manuel Ávila está construido sobre I con la quinta del acorde rebajada, su función tonal podría ser de acorde de dominante con séptima y novena de Fa Mayor (de Mi frigio) o de La Mayor (tono original).

Manuel Ávila comienza el segundo tercio por IV. «El Cojo de Málaga»: I-II-III-IV. Ambos utilizan en la melodía bv. El primero efectúa la cadencia final del tercio en IV, el segundo sobre II. Veamos un ejemplo de «El Cojo de Málaga», la cadencia final la culmina sobre II mediante un intervalo de segunda menor ascendente después de un doble floreo sobre II (Do):

\section{SEGUNDO TERCIO}

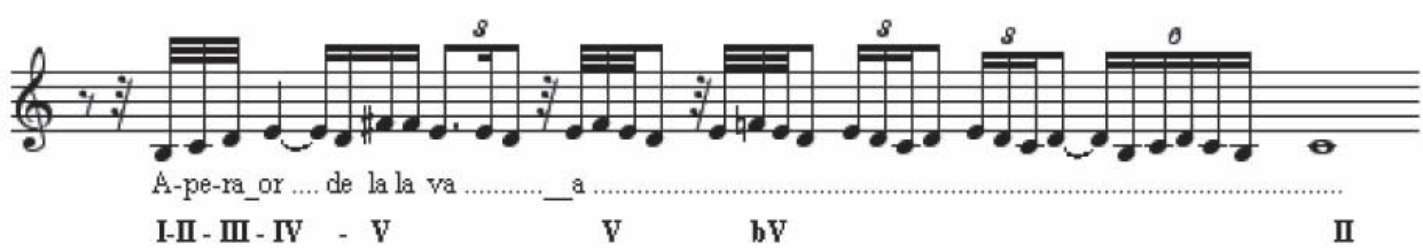

Ejemplo 16. $2^{\circ}$ Tercio, Murciana: "Échese usted al vaciaero”. «El Cojo de Málaga».

Manuel Ávila realiza la cadencia final sobre IV en acceso por segunda menor descendente que corresponde a los grados modales bv y IV. La melodía que antecede a la cadencia está creada en base a la presencia de bv que le confiere un carácter de un canto llano o de una oración cantada:

\section{SEGUNDO TERCIO}

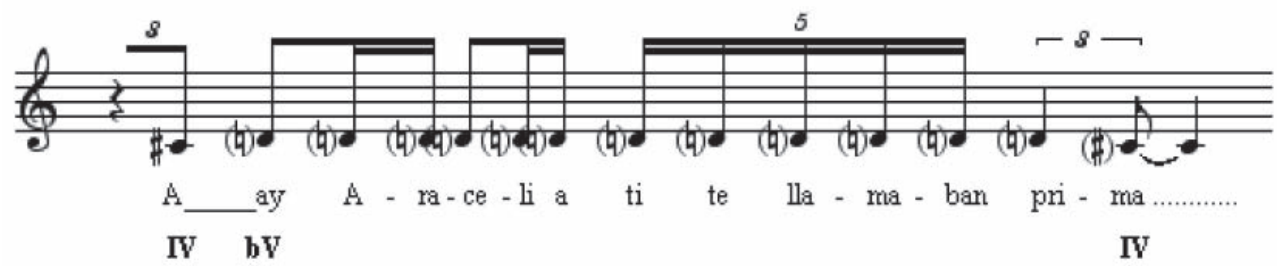

Ejemplo 17. $2^{\circ}$ Tercio. Murciana, Manuel Ávila: “Araceli a ti te llaman”.

Ambos construyen el acorde respuesta con la triada sobre II. Su función tonal podría ser la de un acorde perfecto mayor de Fa Mayor (Mi frigio).

Los dos utilizan en la melodía del tercer tercio bv. «El Cojo de Málaga» comienza por el IV y cadencia en I mediante un intervalo de segunda mayor descendente, con el mismo giro melódico del primer tercio. Veamos el ejemplo: 


\section{TERCER TERCIO}

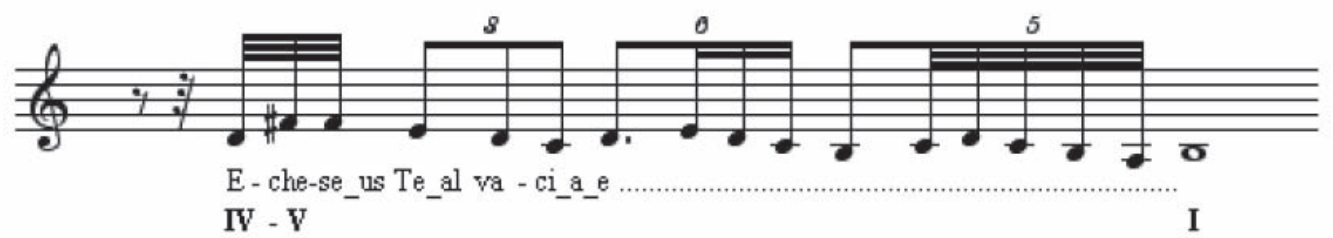

Ejemplo 18. $3^{\circ}$ Tercio, Murciana: "Échese usted al vaciaero". «El Cojo de Málaga».

Manuel Ávila comienza por III-IV-V-VI-VII y cadencia sobre v mediante un intervalo de segunda menor descendente. El giro melódico de la cadencia es similar al de su primer tercio. Veamos un ejemplo:

TERCER TERCIO

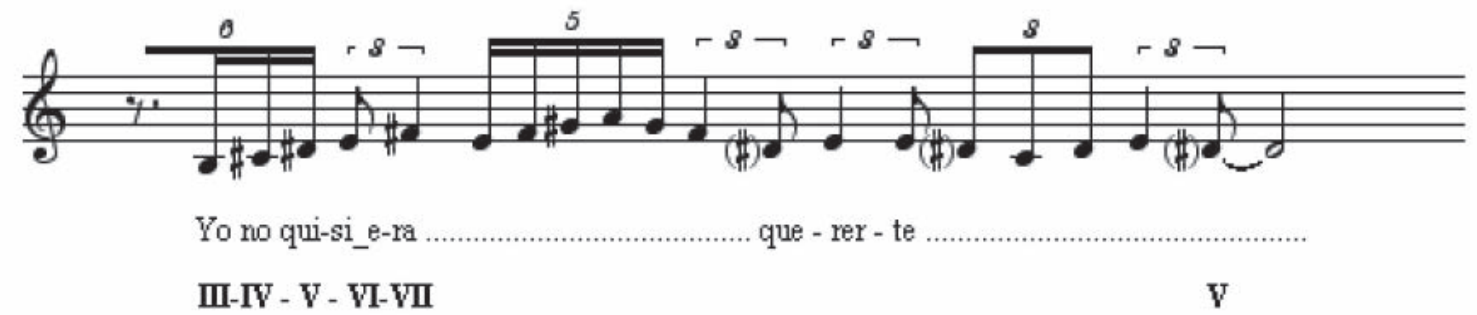

Ejemplo 19. $3^{\circ}$ Tercio. Murciana, Manuel Ávila: “Araceli a ti te llaman”.

El acorde respuesta del Cojo se realiza sobre la triada modal de vi cuya función tonal podría ser de un acorde perfecto mayor de vi. En Manuel Ávila, el acorde respuesta se construye con acorde modal sobre I con su quinta $1 \frac{1}{2}$ tono rebajada, la función tonal podría ser de un acorde de dominante con séptima de II, Fa Mayor (Mi frigio).

El cuarto tercio de Manuel Ávila comienza por III y cadencia en bv. En el siguiente ejemplo podemos ver este esquema cadencial: 


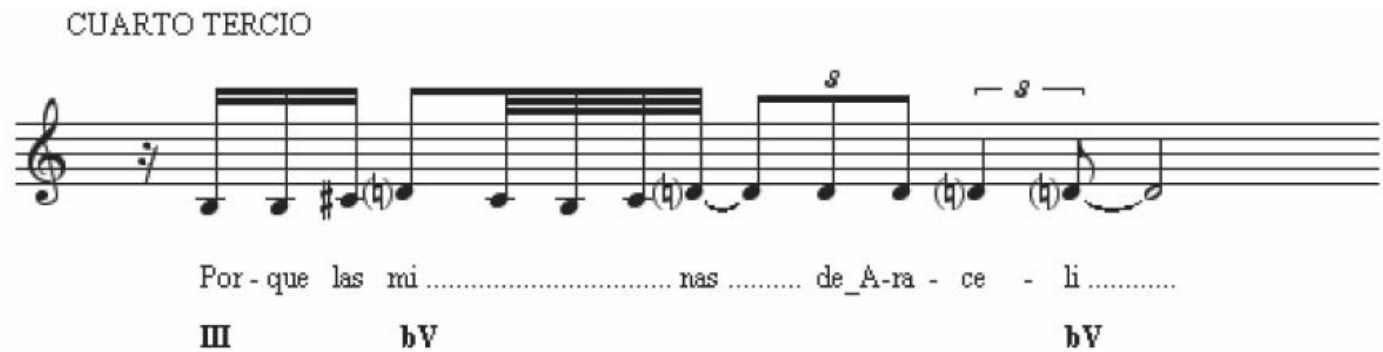

Ejemplo 20. $4^{\circ}$ Tercio. Murciana, Manuel Ávila: "Araceli a ti te llaman".

«El Cojo de Málaga» inicia el cuarto tercio con: I-II-III-IV-III, cadencia sobre II mediante una segunda menor ascendente. En la conclusión cadencial, ejecuta un giro melódico característico que responde a la siguiente secuencia de grados modales: III-IV-III-II-I-II. Veamos el ejemplo:

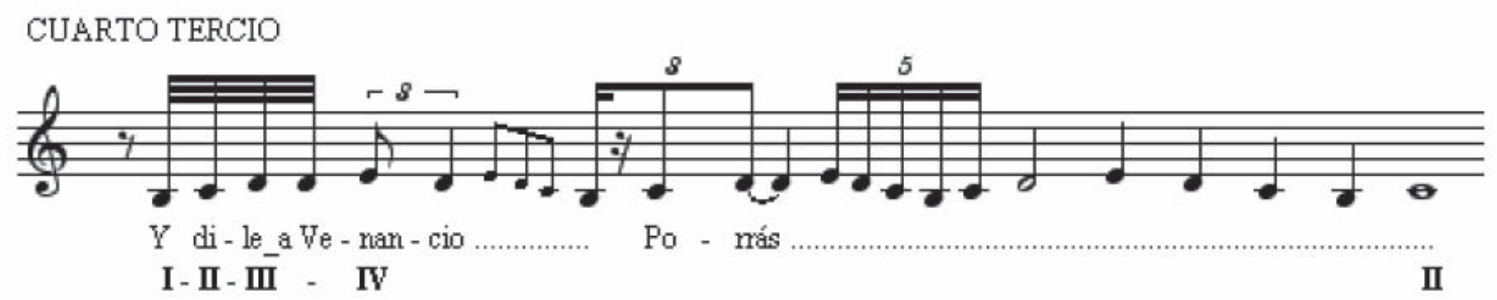

Ejemplo 21. $4^{\circ}$ Tercio, Murciana: "Échese usted al vaciaero". «El Cojo de Málaga».

En ambos casos el acorde respuesta se realiza con la triada construida sobre II. Su función tonal podría ser de un acorde perfecto mayor de II, Fa Mayor (Mi frigio).

En el quinto tercio del «El Cojo de Málaga», ocurre un hecho insólito en la melodía. Usa el tercer grado modal rebajado medio tono que lo indicaré como biII ${ }^{43}$. El quinto tercio comienza por III, alcanza el v y realiza un floreo superior con vi. Sin realizar una cadencia y respuesta de la guitarra definida, comienza con el sexto tercio que liga al remate final mediante la sucesión de grados modales: Iv-bv-IV-

43 Aunque el uso del tercer grado rebajado es puramente anecdótico y de efecto estético, es indudable que en la interpretación aporta un mayor carácter dramático. Si enarmonizamos el tercer grado rebajado medio tono (Do\# en el tono de la Murciana original, Fa\# en Mi frigio), podríamos obtener una correspondencia con la función tonal de una supuesta sensible del tercer grado del modo (en Mi frigio, Sol). A su vez, si considerásemos este grado como la tonalidad del quinto grado de la tonalidad mayor del modo (Do Mayor de Mi frigio), Fa\# se convertiría en la sensible de Sol Mayor, o lo que es lo mismo, podría formar parte, armónicamente hablando, de una función tonal de dominante de la dominante de la tonalidad mayor del modo. 
III-bIII-III, finalmente cadencia en I. El quinto y el sexto tercio quedan unidos en un solo tercio, por tanto, el quinto tercio no tiene acorde respuesta aunque se canta sustentado por la guitarra con la triada modal sobre II. El cante concluye con un acorde sobre la triada mayor de I (Si frigio). Veamos el ejemplo que accede con un intervalo de segunda mayor ascendente hasta i en la cadencia final, cuyo giro melódico característico es: I-II-III-II-I-(-)VII-I:

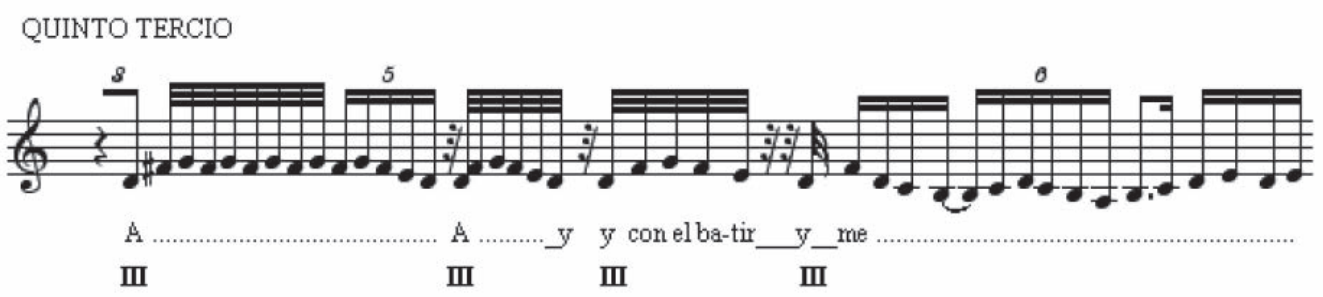

SEXTO TERCIO Tercera rebajada
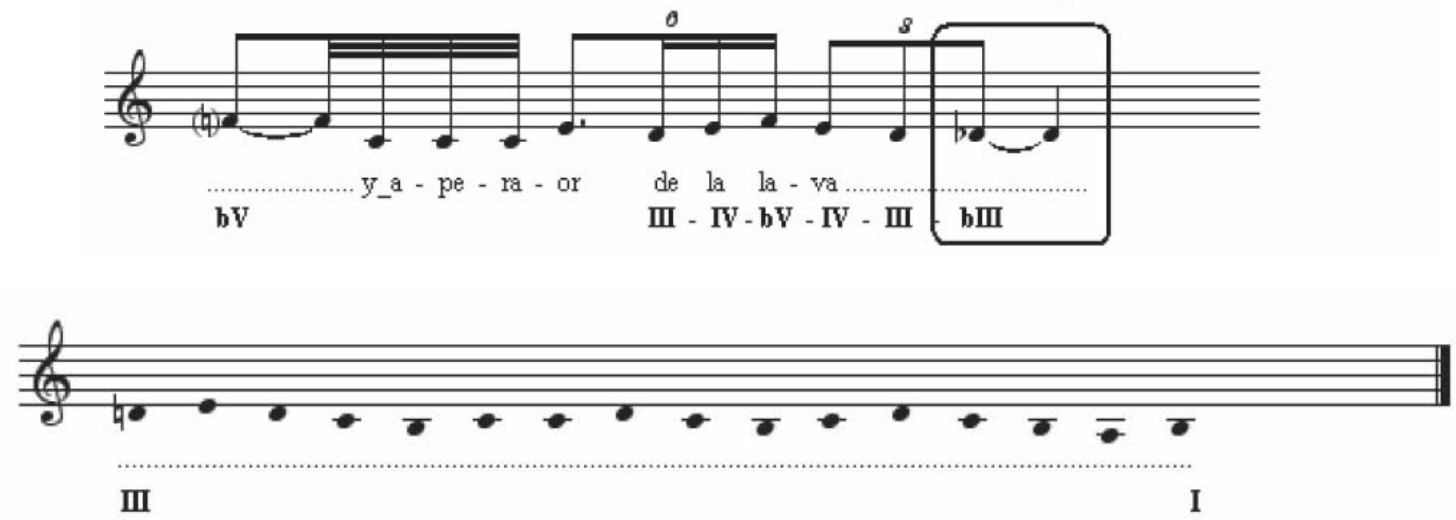

Ejemplo 22. $5^{\circ}, 6^{\circ}$ y Remate Final Tercio, Murciana: “Échese usted al vaciaero”.

Manuel Ávila, diferencia el quinto tercio del sexto. El quinto comienza por III-IV-V-VI-VII y cadencia en $v$ en sentido ascendente mediante una segunda mayor. La progresión de grados modales que utiliza es: V-IV-III-IV-V-IV-III-IV-V-VI-V-IV-V. El acorde respuesta de la guitarra se realiza sobre I con la quinta del acorde rebajada (bv). La función tonal podría corresponder a un acorde de dominante con séptima de Fa Mayor (de Mi frigio, La Mayor en el tono del modo original de la Murciana). Veamos el ejemplo: 
QUINTO TERCIO

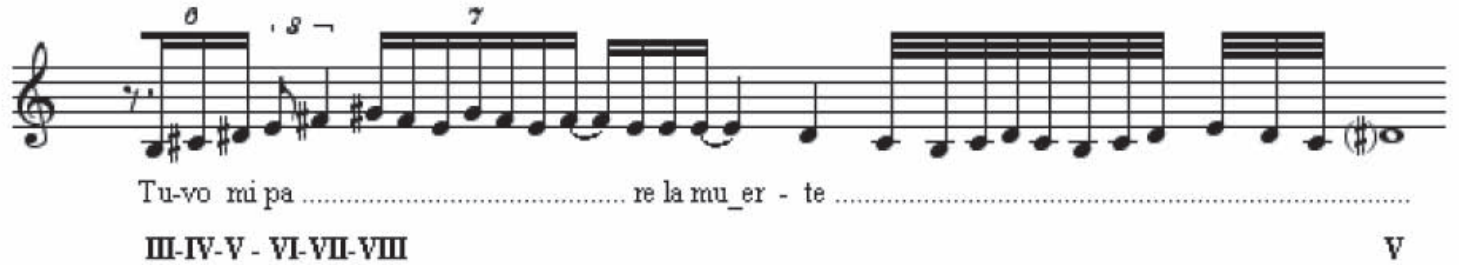

Ejemplo 23. $5^{\circ}$ Tercio, Murciana: "Échese usted al vaciaero". «El Cojo de Málaga».

Manuel Ávila inicia el sexto tercio por Iv-bv dividido en dos secciones. La primera sección cadencia en bv, la segunda la enlaza con el remate final cuya cadencia se realiza sobre el i que la guitarra mayoriza. La melodía utiliza bv, el cante es sostenido por la guitarra mediante la triada modal sobre II. La cadencia final se antecede de un intervalo de segunda menor descendente. Veamos el ejemplo de la transcripción:

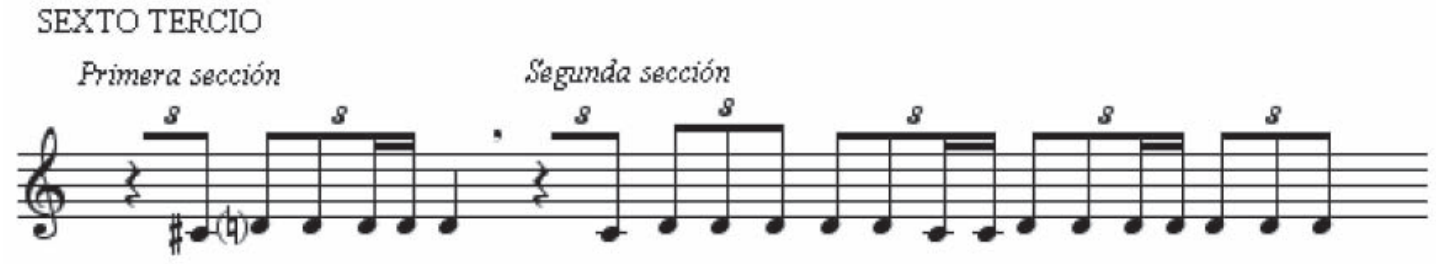

A ay Ara.ce-li

A ti - te lla-ma - ban te - lla-ma-ban en el ba-mi_o...
IV - bV
bV
IV $-\mathbf{b V}$
bV

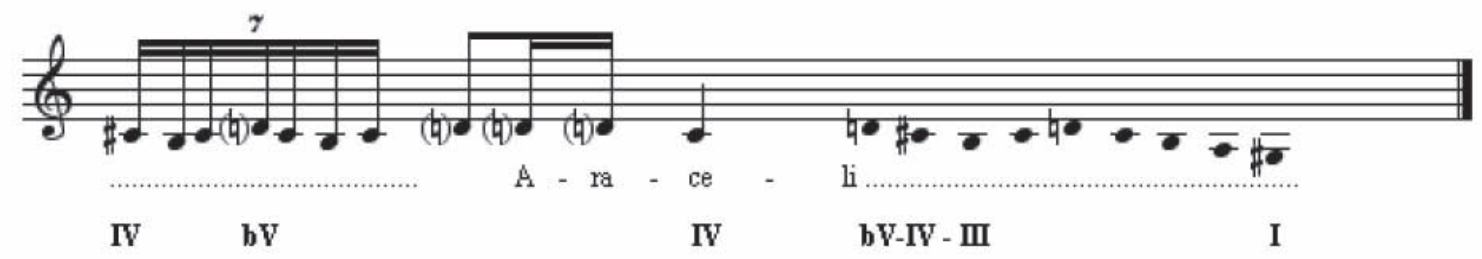

Ejemplo 24. $5^{\circ}$ Tercio y Remate Final Murciana: "Échese usted al vaciaero". «El Cojo de Málaga». 


\section{Cuadro Esquemático Cadencial de La Murciana en Mi frigio:}

\begin{tabular}{|c|c|c|}
\hline $\begin{array}{l}\text { Nombre de la parte correspon- } \\
\text { diente a la estructura formal }\end{array}$ & $\begin{array}{l}\text { Grado modal sobre el que caden- } \\
\text { cia la voz. }\end{array}$ & $\begin{array}{l}\text { Respuesta de la guitarra correspon- } \\
\text { diente al acorde tonal. }\end{array}$ \\
\hline Introducción & & Mi Mayor (Tercera mayorizada). \\
\hline \multirow[t]{2}{*}{ Salida } & Primera Sección II & II como Fa Mayor. \\
\hline & Segunda Sección I & Mi mayorizado \\
\hline \multirow[t]{2}{*}{$1^{\circ}$ Tercio } & I (El cojo de Málaga) & $\begin{array}{l}\text { I como dominante con séptima de } \\
\text { Do Mayor. }\end{array}$ \\
\hline & v (Manuel Ávila) & $\begin{array}{l}\text { I como dominante de Fa Mayor con } \\
\text { Sib. }\end{array}$ \\
\hline \multirow[t]{2}{*}{$2^{\circ}$ Tercio } & IV (El cojo de Málaga) & II como Fa Mayor. \\
\hline & II (Manuel Ávila) & II como Fa Mayor. \\
\hline \multirow[t]{2}{*}{$3^{\circ}$ Tercio } & I (El cojo de Málaga) & vi como Do Mayor. \\
\hline & v (Manuel Ávila) & $\begin{array}{l}\text { I como dominante de Fa Mayor con } \\
\text { Sib. }\end{array}$ \\
\hline \multirow[t]{2}{*}{$4^{\circ}$ Tercio } & II (El cojo de Málaga) & II como Fa Mayor. \\
\hline & bv (Manuel Ávila) & II como Fa Mayor. \\
\hline \multirow[t]{2}{*}{$5^{\circ}$ Tercio } & I (El cojo de Málaga) & Sin respuesta clara... \\
\hline & v (Manuel Ávila) & $\begin{array}{l}\text { I como dominante de Fa Mayor con } \\
\text { Sib. }\end{array}$ \\
\hline $6^{\circ}$ Tercio & & $\begin{array}{l}\text { Se mantiene sobre II como Fa Ma- } \\
\text { yor. }\end{array}$ \\
\hline Remate Final & I & $\begin{array}{l}\text { Cadencia Flamenca, Mi mayoriza- } \\
\text { do. }\end{array}$ \\
\hline
\end{tabular}


El uso que de este cuadro esquemático se pude hacer, de manera inmediata, gracias a la información que nos presta desde el punto de vista de su estructura formal y el comportamiento musical que atiende a la morfología propia de la melodía y las cadencias modales y tonales, es el de prestar un servicio a futuros materiales destinados al aprendizaje de la práctica y teoría del cante minero y su acompañamiento. Con ello podría enriquecer, desde una perspectiva musical y estética, nuevas versiones que ayuden a crear en La Murciana un estilo vivo que evolucione en base a sus patrones musicales establecidos en el cuadro esquemático. Además puede facilitar nuevas vías de propuestas creativas que basen su contenido en lenguajes neo-modales y neotonales, indicadas y sintetizadas en el cuadro esquemático anteriormente expuesto. Por último, también podrá proporcionar aquellas recurrencias creativas asociadas a lenguajes de vanguardias que yo mismo he podido experimentar y que también me servirán en posteriores trabajos creativos. Es por ello que he creído conveniente, a lo largo de este artículo, analizar La Murciana desde sus más diversas vertientes, desde su origen como cante minero hasta su comportamiento musical, pasando por el contenido de la letra minera y la estructura formal del cante, siempre al servicio de la información que me permitiera adiestrarme en los cantes mineros y que permitiera inspirarme, de la mejor manera posible, para abordar futuros proyectos relacionados con la composición musical.

\section{Bibliografía Citada}

- García Gómez, G.: Cante flamenco, cante minero, una interpretación sociocultural. Barcelona-Murcia, Anthropos y Editora Regional de Murcia, 1993.

- Gerardo, J. y Belade, F.: Sociedad y Cante Flamenco, el cante de las minas. Murcia, Editora Regional de Murcia, 1985.

- Sáez García, A.: La Copla Enterrada. La Unión, Ayuntamiento de La Unión, 1998.

- Salom Amengual, A.: Los Cantes Libre de Levante. Murcia, Editora Regional de Murcia, 1982.

\section{Bibliografía Complementaria}

- Bautista Vilar, J.; Egea, P. M. \& Moreno, D. V.: El Movimiento Obrero en el Distrito Minero de Cartagena-La Unión. Valencia, Centro editorial de Servicios y Publicaciones Universitarias, 1986.

- Benavente, J. M.: Aproximación al Lenguaje Musical de J. Turina. Madrid, Alpuerto, 1983.

- Bernal Velasco, E.: Crónica personal de las primeras once ediciones del "Festival Nacional del Cante de las Minas”. Murcia, Cajamurcia, 2001.

- Blas Vega, J.: "Boceto Para Una Historia del Cante de las Minas", en El Cante de las Minas. Madrid, Hispavox, 1970, HHS 10-371.

- CÁmara de Landa, Enrique: Etnomusicología. Madrid, Ediciones del iccmu, 2003. 
- Fernández Marín, L.: Teoría Musical del Flamenco. San Lorenzo del Escorial, Acordes concert, 2004.

- Gómez Gómez, M. A.: Catálogo Discográfico de Los Cantes Mineros. Murcia, Universidad de Murcia, 1995.

- Lámpara Minera. Xui Festival Nacional del Cante de Las Minas, La Unión, 2001.

- Lámpara Minera. Xli Festival Nacional del Cante de Las Minas, La Unión, 2002.

- Manrique López, J. \& Alba Villagrán, D.: Los Cantes de La Unión y Cartagena. Barcelona, Casa Regional de Murcia y Albacete, 1978.

- Navarro, J. L.: “Cantes mineros: de Almería a La Unión”, en Rito y Geografía del Cante Jondo. Murcia, Alga, 1997.

- Navarro, J. L. \& Iino, A.: Cantes de las minas. Córdoba, Ediciones de la Posada, 1989.

- Parra Pujante, A.: "Las cenizas anónimas de «El Rojo el Alpargatero»", en El Papa Flamenco. Murcia, Excmo. Ayuntamiento de La Unión, 1972.

- Ríos Ruiz, M.: El Gran Libro del Flamenco. Vol.1. Madrid, Calambur, 2002.

- SÁez García, A.: Crónicas del Festival Internacional del Cante de las Minas. La Unión 19611962. La Unión, Excmo. Ayuntamiento de la Unión, 1992.

- SÁez García, A.: Cantar en La Unión. Murcia, Excmo. Ayuntamiento de la Unión, 1994.

- SÁez García, A.: La Unión aproximación a su etnología. La Unión, Excmo. Ayuntamiento de La Unión, 1988.

- Saulnier, D.: Los Modos Gregorianos. Abbaye Saint-Pierre/Solesmes, La Froidfontaine, 2001.

- Steingress, Gerard: Flamenco Posmoderno: Entre tradición y heterodoxia. Un diagnóstico sociomusicológico. Sevilla, Signatura Ediciones de Andalucía, 2006.

\section{Discografía}

- Antología del Cante Minero y Levantino, Vol. 2.: PIÑAnA, Antonio: Madrid, Universal Music Spain [un-900 LC01846], 1999.

- Antología del Cante Flamenco. Madrid, Hispavox, 1998.

- “Antonio Piñana”, en El Cante de las Minas. Madrid, Hispavox, 1970.

- Antonio Piñana. Vol. 8 y 9. Madrid, Triumph, 1972.

- Cante de las Minas, Vol. 1. Granada, Big Bang, 1996.

- Cante de las Minas, Vol. 3. Granada, Big Bang, 1998.

- Curro Piñana, De la vigilia al alba. Madrid, RTVE-Música, 2004.

- “D. Antonio Chacón”, en Cantaores de Época, Vol. 1. Utrera (Sevilla), Fonografía del Sur, [SE-50-CD2239], 1998.

- Desolación de la Quimera. Madrid, RTVE-Música, 2003.

- Festival Nacional del Cante de las Minas. Antología, vol. 1. Prado del Rey (Madrid), RTve, M-31744-2000, 2000. 
- Festival Nacional del Cante de las Minas, Antología, vol. 2. Prado del Rey (Madrid), RTve, M-17026-2001, 2001.

- Festival Nacional del Cante de las Minas, Antología, vol. 3. Prado del Rey (Madrid), RTVe, M-18497-2002, 2002.

- Festival Nacional del Cante de las Minas, Antología, vol. 4. Prado del Rey (Madrid), RTVe, M-23690-2003, 2003.

- Festival Nacional del Cante de las Minas, Antología, vol. 5. Prado del Rey (Madrid), RTVE, M-25534-2004, 2004.

- "El Cojo de MálagA": Historia del Flamenco. Sevilla, Ediciones Tartesos, "Testimonios Flamencos, vol. 40", no pone año de producción del CD, el año de grabación del cante utilizado es 1921

- Por Tarantas, Tarantos, Cartageneras y Mineras. Madrid, Emi-Odeón, 724358226522, 2003.

Recibido: $17 / 10 / 2008$

Aceptado: 20/10/2008 